DR RICHARD HILL (Orcid ID : 0000-0003-0394-6048)

Article type : Review

\title{
Modulating Autophagy as a Therapeutic Strategy for the Treatment of Paediatric High Grade
} Glioma.

Alison Howarth ${ }^{1}$, Patricia A. Madureira ${ }^{1-2}$, George Lockwood ${ }^{3}$, Lisa C. D. Storer ${ }^{3}$, Richard Grundy ${ }^{3}$, Ruman Rahman ${ }^{3}$, Geoffrey J. Pilkington ${ }^{1}$, Richard Hill ${ }^{1}$.

1. Brain Tumour Research Centre, Institute of Biomedical and Biomolecular Sciences, IBBS, University of Portsmouth, PO1 2DT, UK

2. Centre for Biomedical Research (CBMR), University of Algarve, Campus of Gambelas, Building 8, Room 3.4, 8005-139 Faro, Portugal

3. Children's Brain Tumour Research Centre, School of Medicine, Queen's Medical Centre, University of Nottingham, NG7 2UH, UK

Corresponding Author:

Brain Tumour Research Centre, Institute of Biomedical and Biomolecular Sciences, IBBS, University of Portsmouth, PO1 2DT, UK (+44) 2392 842118, Richard.Hill@port.ac.uk

\section{Abstract}

Paediatric high grade glioma ( $\mathrm{pHGG)}$ ) represent a therapeutically challenging group of tumours. Despite decades of research there has been a minimal improvement in treatment and the clinical prognosis remains poor. Autophagy, a highly conserved process for recycling metabolic substrates is upregulated in pHGG, promoting tumour progression and evading cell death. There is significant cross talk between autophagy and a plethora of critical cellular pathways, many of which

This article has been accepted for publication and undergone full peer review but has not been through the copyediting, typesetting, pagination and proofreading process, which may lead to differences between this version and the Version of Record. Please cite this article as doi: 10.1111/bpa.12729

This article is protected by copyright. All rights reserved. 
are dysregulated in pHGG. The following article will discuss our current understanding of autophagy signalling in pHGG and the potential modulation of this network as a therapeutic target.

\section{Introduction}

Paediatric high grade glioma ( $\mathrm{pHGG)}$ are aggressive and difficult to treat central nervous system tumours (1) and include grade III anaplastic astrocytoma, grade IV glioblastoma (GBM) and grade IV diffuse intrinsic pontine glioma (DIPG) (2). Despite significant research, a large number of clinical trials and improvements in pre- and intra-operative surgical imaging techniques, there has been little clinical improvement for these patients (3). The mean 2 year survival is between 10 and $30 \%$ for pHGG patients, and is less than $1 \%$ for DIPG patients $(4,5)$. There remains no standard treatment regimen for pHGG patients (6) and current therapy incorporates, where possible, gross maximal surgical resection, focal, fractionated radiotherapy, concomitant with, and followed by, aggressive combinatorial chemotherapy regimens (7-10).

In patients under 5 years of age, radiotherapy may be spared or delayed to minimise irreversible neurocognitive sequalae which include neurological, endocrine function and cognitive impairment (11-13). Surgical resection is constrained within this patient population by tumour location which typically presents in proximity to functionally eloquent areas of the brain. Where surgery is not feasible, a biopsy may be taken for diagnostic and research purposes (14). The complete excision of the tumour is further complicated by the infiltrative nature of high grade neoplastic cells at the tumour border which invade into healthy brain parenchyma, a hallmark of pHGG. The cells that infiltrate into the surrounding non-neoplastic tissues typically undergo mitotic arrest and are highly resistant to conventional therapies that target rapidly dividing cells (15). Treatment is further complicated as the effective delivery of chemotherapeutics is impeded by the blood-brain barrier (BBB) which inhibits cytotoxic agents from permeating into the tumour. Furthermore, pHGGs are highly vascularised and demonstrate rapid and widespread remodelling of the vascular network to meet the metabolic demands of the tumour. Consequently, newly recruited blood vessels are disorganised and display increased fenestrations with weak, leaky vessel walls. These generate high interstitial pressure gradients, causing stagnated blood flow and excess fluid retention (16). Together, modulation of the vascular unit creates an extremely challenging clinical situation. The pHGG therapeutic has to cross the BBB, attain a therapeutically effective dose, and be retained at this concentration to mediate an effective clinical response. While adult high grade glioma treatments have been developed, including the Stupp protocol where there is the incorporation of temozolomide (TMZ) with concomitant radiotherapy, these have not translated into

This article is protected by copyright. All rights reserved. 
the paediatric population (7). The methylation of the $O^{6}$-methylguanine-DNA-methyltransferase (MGMT) promoter predicts a subset of adult patients that are likelier to respond to TMZ treatment (17). In pHGG, MGMT promoter methylation, occurs in $~ 40 \%$ of patients, similar to that observed in aHGG. However, irrespective of MGMT promoter methylation status, TMZ treatment regimens have minimal benefit in PHGG patients. These data suggest an alternate, but as yet, poorly understood resistance mechanism in paediatric patients (18). Within the last decade our understanding of pHGG pathobiology has significantly increased. The identification of unique epigenetic and genetic driver mutations define specific patient subgroups. These correlate with tumour location, patient age and ultimately prognosis. Together, the molecular profiles of these tumours provide further compelling evidence for pHGG to be considered distinct diseases from their adult counterparts $(4,19-21)$.

Recent molecular meta-analysis has described distinct molecular subgroups in pHGG and DIPG tumours (22). The discovery of histone H3.3 (H3F3A) and H3.1 (HIST1H3B) K27M and G34R/V mutations that occur almost exclusively in paediatric tumours, has been a major step forward in the reclassification of these diseases. In light of this, the World Health Organisation (WHO) updated brain tumour classifications to reflect the novel group 'diffuse midline glioma with H3K27M mutation' to create more clinically relevant subtypes (22). Within histone mutant subtypes, further segregation occurred according to additional somatic co-mutations. Histone H3.3 G34R/V, restricted to the cerebral hemisphere, occurred with co-mutations of TP53, ATRX and F-box/WD repeatcontaining protein 7 (FBXW7). FBXW7 has been shown to promote MYC/MYCN signalling while the H3.3 G34R/V mutants were the only subgroup to harbour MGMT promoter methylation (22). H3.3 K27M mutant tumours were present in over $60 \%$ of midline pHGG and DPIG tumours, and this mutation correlated with worse clinical prognosis. Co-mutations in PDGFR and FGFR1, were also noted in the H3.3 K27M tumours (4). These were alongside mutations in TOP3A, TP53, PPM1D and CCND2. In contrast, H3.1 K27M mutant tumours were exclusively restricted to the pons and correlated with significantly improved clinical prognosis. Co-mutations in the PI3K signalling pathway and activin A receptor, type I (ACVR1) were also common within this sub-group.

These data are compelling and a thorough understanding of tumour pathobiology, including specificity in histone mutation and co-mutation expression may be key to defining clinically actionable sub-groups (22). However, care must be taken not to over-segregate tumour types into smaller and smaller patient cohorts as statistically relevant numbers for clinical trial enrolment may be difficult to achieve. Tumour reliance on common pathways including autophagy may prove a route to therapeutic intervention. This could be targeted alongside specific therapeutics according to specific intragroup co-mutations. The heterogeneity of pHGG tumours has resulted in many failed Phase II and III clinical trials using various small molecule inhibitors (4). Therapeutically targeting

This article is protected by copyright. All rights reserved. 
common pathways, including autophagy across multiple tumour subgroups, in combination with subgroup or mutation specific therapeutics has attracted significant interest. This has driven a shift in focus to broader scale combinatorial approaches that target survival pathways in an attempt to sensitise pHGG cells to therapeutic intervention, potentially improving efficacy by circumventing resistance and off target effects $(19,23)$.

\section{Autophagy.}

Autophagy is a catabolic process in which cellular components are degraded and recycled. Autophagy is regulated by, and in turn regulates, multiple signalling pathways, many of which are deregulated in pHGG and targetable with various inhibitors. It is hypothesised that a combinatorial therapeutic approach targeting essential pHGG survival pathways in addition to autophagy could overcome resistance mechanisms and provide an effective treatment of pHGG (24-27). Within this review we also include some of our own data which indicates targeting autophagy as an attractive therapy modality for pHGG.

Autophagy is a homeostatic process by which cellular components are cycled to make available essential substrates (28). Cellular components for degradation are tagged and sequestered into double membraned vesicles. Fusion of these double membraned vesicles with a lysosome leads to the complete degradation of the contents, which are released into the cytoplasm (29). Autophagy occurs at a basal level in all cells, acting as a means to generate essential substrates or release sequestered molecules from long term stores (30). In response to stress or insult, including the action of chemo- and radio-therapy, autophagy is upregulated to provide essential substrates for growth and continued cell proliferation. First described in yeast, over 30 mammalian autophagy gene $(A T G)$ homologues have been identified. The term 'autophagy' covers a range of mechanisms. These may act at a broad level termed macro-autophagy, or in a highly specific, orchestrated manner referred to as micro-autophagy. Autophagy can denote to the targeting of specific organelles, or occur in the absence of membrane vesicles (termed chaperone-mediated autophagy, CMA) (30) (31). An overview of these processes are shown in Figure 1.

Microautophagy is at present poorly characterised, and the major proteins involved are as yet undefined in mammalian systems. Micro-autophagy is selective and is initiated by direct invagination of the endosomal or lysosomal membrane. Deformation and invagination of the membrane forms the autophagic tube, extending into the vacuole and encapsulating cytoplasmic contents. Extension of the autophagic tube occurs as transmembrane proteins are removed, resulting in lipid enrichment

This article is protected by copyright. All rights reserved. 
of the membrane. The proximal end of the tube expands to form the autophagic body which eventually fuses, engulfing the cytoplasmic contents. The fused autophagic body is untethered by scission and along with the contents, are degraded by hydrolases (32).

Chaperone-mediated autophagy (CMA) plays an important role in transcriptional regulation, targeting transcription factors and associated inhibitors for degradation. CMA is upregulated in response to nutrient deprivation, toxic and oxidative stress. Selective protein recognition relies on presentation by the target protein of a KFERQ-motif, present in around $30 \%$ of cytosolic proteins. This recognition motif is usually inaccessible due to the $3 \mathrm{D}$ structure of protein: protein complexes. The KFERQ-motif becomes accessible via protein misfolding, partial protein unfolding or protein: protein dissociation (33). Presentation of the KFERQ-motif by individual proteins initiates the binding of heat shock protein 70 (hsp70) and additional co-chaperone proteins. The subsequent hsp70/substrate complex localises to the lysosomal membrane. This binding is mediated by Lysosomal Associated Membrane Protein-2A (LAMP-2A) and the lysosmal-heat shock protein 90 complex. Once bound, the target protein is unfolded and translocated into the lysosomal lumen where it is degraded (34). In this way, recognition motif presentation by target proteins and the highly orchestrated cycling of LAMP-2A levels tightly regulate CMA (35).

Mitophagy, or selective autophagy, is highly specific, targeting damaged or dysfunctional mitochondria. Mitophagy is regulated by PINK1 (PTEN-induced putative kinase) and Parkin (Parkin RBR E3 Ubiquitin Protein Ligase) which recognise dysfunctional mitochondria and initiate their autophagic engulfment. In healthy mitochondria, PINK1 binds to the mitochondrial membrane and is rapidly imported into the inner mitochondrial membrane where it is cleaved and afterward degraded by proteolysis. This rapid turn-over maintains a dynamic, but low cellular pool of PINK1. Following mitochondrial damage, the import and cleavage of PINK1 is inhibited (36). Unprocessed PINK1 rapidly accumulates on the surface of depolarised mitochondrial membranes. In the unprocessed state, PINK1 recruits cytosolic Parkin, an ubiquitin ligase. The exact mechanism by which this occurs is currently unknown. The binding of PINK1 and Parkin immobilises damaged mitochondria and prevents their interaction within the mitochondrial network. Parkin also mediates hyper-ubiquitination of the mitochondrial membrane, which is subsequently recognised by the ubiquitin-interacting autophagy proteins p62 and Lys63. At this stage the mitophagy and autophagy processes merge, where the machinery driving downstream engulfment and degradation are shared (36). At present, the exact mechanisms of mitophagy induction and its regulation are only just being uncovered.

This article is protected by copyright. All rights reserved. 
Macroautophagy is an essential, conserved self-eating process that cells perform to allow the degradation of intracellular components which include soluble proteins, aggregated proteins, organelles, macromolecular complexes, pathogens. The dysregulation of macroautophagy has been implicated in many diseases including cancer. For this review, the term 'autophagy' refers to macroautophagy (37). Autophagy regulates many different biological processes during development, normal physiology, and in response to a wide variety of stresses.

Autophagy and the associated networks that interplay with this process (summarized in Figure 2 ) is controlled by growth factors and energy-sensing proteins, including the master autophagy regulator, the mammalian target of rapamycin (mTOR). The mTOR protein inhibits autophagy signalling when adequate nutrients are present. The adenosine monophosphate-activated protein kinase (AMPK) is an important regulator of mTOR (38). AMPK is activated by a decreasing ATP to AMP ratio and responds to this ratio change by reducing ATP-dependent processes within the cell. This leads to the phosphorylation and activation of Tuberous sclerosis proteins 1 and 2 (TSC1/TSC2) and inhibits the formation of the mTOR complex (Figure 2, network shown in green). This inhibition allows the formation of the ULK1 protein complex, itself directly activated by AMPK and the subsequent initiation of autophagy (Figure 2 shown in red). AMPK may also directly interact with and inhibit mTOR complex 1 (mTORC1), via phosphorylation of the Raptor subunit, inducing autophagy (39). Activation of the AMPK signalling pathway leads to phosphorylation and stabilisation of cyclindependant kinase inhibitor p27, a key cell cycle inhibitor, stimulating autophagy in an attempt to provide sufficient substrates for cell cycle progression (40). Hypoxia, generated when the cellular oxygen demand is higher than oxygen availability stimulates autophagy signalling by activating Beclin1 and AMPK, inhibiting mTORC1. This promotes autophagy signalling via BNIP3 (Bcl2 interacting protein-3) and ATG5 (Figure 2). Interestingly, hypoxia-induced autophagy is independent of hypoxia inducible factor (HIF), commonly elevated and observed in pHGG (41). Elevated cytokine signalling leads to the activation of AMPK-ULK1 and inhibition of mTORC1, inducing autophagy. Conversely, cytokines have also been shown to impair lysosomal function, blocking autophagic flux (42). Interestingly, cytosolic $\mathrm{Ca}^{2+}$ has been shown to trigger autophagy by interaction with AMPK, the c-Jun N-terminal kinase (JNK) and mTORC (Figure 2, shown in grey). Conversely, low levels of intracellular $\mathrm{Ca}^{2+}$, partially mediated by $\mathrm{Ca}^{2+}$ sequestration into the mitochondria has been shown to inhibit autophagy (Figure 2, shown in purple) (43).

Under nutrient rich conditions, mTORC1 associates with the ULK1 and ULK2 protein complexes. The UNC-51-like kinase-1-FIP200 (FAK family kinase-interacting protein of 200kDa)ATG12-ATG101 complex phosphorylates ULK1, ULK2 and ATG13. Where nutrients are depleted, mTORC1 dissociates from the ULK1/2-ATG13 complex and mTORC1 activity is repressed. ULK1 and

This article is protected by copyright. All rights reserved. 
ULK2 phosphorylate both FIP200 and ATG13 and the entire complex translocates to the phagophore assembly site. Under these conditions Beclin-1 is activated by ULK1 and ULK2, leading to the formation of the Beclin-1/hVPS34 (human vacuolar sorting protein-34)/p150 complex. This complex is required for protein recruitment to drive phagophore initiation and early autophagosome membrane synthesis. The transmembrane proteins ATG9 and vacuole membrane protein (VMP1) recruit lipids to the phagophore assembly site mediating autophagosome membrane elongation. Cellular components for degradation are tagged with Lys63 cargo recognition protein and sequestered into the double membrane phagophore during continued autophagosome membrane elongation. The maturation of the autophagosome relies on two ubiquitin-like (UBL) conjugation systems which partially overlap. These are ATG12 and light chain 3 (LC3). ATG12 UBL conjugation is initiated by the covalent binding of ATG12 to ATG5, catalysed by ATG7 and ATG10. The ATG12-ATG5 complex binds to ATG16, forming the ATG12-ATG5-ATG16 protein complex which interacts with the LC3 UBL system. The ATG4 protease cleaves LC3, followed by the covalent binding of LC3 to phosphatidylethanolamine (PE), a cleavage event required for membrane elongation, cargo recognition, cargo sequestration, and autophagosome maturation. The mature autophagosome fuses with a lysosome and following this fusion, the autophagosome and contents are degraded and then released back into the cytoplasm $(28,44)$. Lipidated LC3 (LC3-II) remains bound to the inner membrane of the autophagosome throughout the maturation and degradation processes, providing a useful marker for monitoring autophagy $(45,46)$.

Chemotherapeutic insult may induce autophagy independent of ATG5, ATG7 and LC3-II. In addition, autophagy induction due to glucose restriction may occur independent of ULK1 (47). Key to ULK1 independent autophagy is that mTOR activity no longer needs to be suppressed. Critically, both ULK-dependent and ULK-independent autophagy involve the common autophagic programme that includes LC3 processing and ATG5 function.

Autophagy is a tightly regulated process, acting at different times as both a pro-survival or cell death pathway (30). Autophagic cell death is termed Type II cell death and typically acts independently of apoptosis (programmed, or type I cell death). Autophagy and apoptosis demonstrate a degree of exclusivity although through common upstream signalling proteins, can cross regulate each other (48). One of the main routes where autophagy can reduce the propensity to induce apoptosis is by mitophagy (36). Mitochondria are the cellular epicentres where prosurvival and pro-death signals merge and cell fate following diverse cellular stresses (including chemotherapy assault) is decided. Consequently, damaged mitochondria are primed to instigate apoptosis and their removal by autophagy can increase the strength of the signal required to induce apoptosis (36). Similarly, autophagy can reduce the amount of pro-apoptotic proteins within the

This article is protected by copyright. All rights reserved. 
cytoplasm, particularly of potent inducers such as Bax and caspase $8(49,50)$. Conversely, autophagy can promote apoptosis by the depletion of endogenous inhibitors of apoptosis, a response observed in a number of genetic model organisms where developmental apoptotic events are abolished following the loss of critical ATGs $(51,52)$. In addition, ATG7 elevates apoptosis following photodamage, directing lysosomal membrane permeabilisation that leads to apoptosis $(53,54)$. The relationship between apoptosis and autophagy is highly context dependent and the subject of widespread debate. However, similar to apoptosis, the dysregulation of autophagy has been identified in a number of diseases, including inflammatory and neurodegenerative diseases and, of particular interest for this review article, cancer (55).

Advances in genomic profiling and multi-centre collaborative projects, notably The Cancer Genome Atlas (TCGA) (56-58) have identified epigenetic and genetic mutations in pHGGs, harbouring aberrations in core signalling pathways that include p53 (26), RAS/RAF/MEK/Erk (59), PI3K/AKT/mTOR $(60,61)$ and RTK/Ras/PI3K $(4,56)$ (Figure 2). Frequently mutated in pHGG, these pathways regulate, or are regulated by autophagy. Consequently, these are highly promising therapeutic targets.

\section{The PI3K/AKT/mTOR Signalling Network.}

The phosphoinositide-3-kinase (PI3K) signalling network is extensive and regulates a plethora of cellular processes including proliferation, cell survival and metabolism (62) (Figure 2 shown in green). PI3K signalling is one of the most frequently mutated pathways in all cancers $(63,64)$. The PI3K family of lipid kinases activate signalling cascades that are mediated by diverse signalling effectors, including G-protein coupled receptors (GPCR), receptor tyrosine kinases (RTK) and cytokines (65). Dysregulation of this network is a hallmark of cancer, particularly pHGG, driving and maintaining an oncogenic phenotype that includes uncontrolled cell growth and division, widespread metabolic alterations, genomic instability and chemotherapy resistance (66). A further group of PI3K related serine/threonine protein kinases (phosphatidylinositol-3-kinase related PIKKs) include ataxia telangiectasia mutated (ATM), ataxia telangiectasia and Rad3-related (ATR), DNAdependent protein kinase (DNA-PK) and the autophagy master regulator mTOR. Each of these are capable of regulating autophagy in response to DNA damage (67). In canonical PI3K signalling, following ligand binding and activation of a membrane bound receptor, class I PI3K's phosphorylate phosphatidylinositol-4,5-bisphosphate $\left(\mathrm{PIP}_{2}\right)$, forming phosphatidylinositol-3,4, 5-bisphosphate $\left(\mathrm{PIP}_{3}\right)$ (68). PIP 3 recruits AKT and PDK1 to the plasma membrane by direct binding. PDK1 phosphorylates the activation loop of AKT, allowing AKT to regulate downstream pathways including the p53

This article is protected by copyright. All rights reserved. 
network, protein synthesis and autophagy (69). PI3K signalling via $\mathrm{PIP}_{3}$ is negatively regulated by the phosphotensin homolog (PTEN), via dephosphorylation of $\mathrm{PIP}_{3}$ to $\mathrm{PIP}_{2}(70)$. PI3K signal activation is associated with poor patient prognosis and is common to both adult and paediatric HGG. However, the mechanisms of PI3K signal activation differ significantly between the adult and paediatric disease (71). In adult high grade glioma, inactivating PTEN mutations are commonly observed. However, in pHGG patients, PTEN mutations are rarer and more commonly display loss of heterozygosity. Furthermore, the inhibition of PTEN following PTEN promoter methylation has been reported (22). Overall, the PI3K signalling pathway has been implicated in a high proportion of pHGG tumours and the PI3K network remains an attractive therapeutic target, in particular mTOR inhibitors.

\section{Regulation of the PI3K/AKT/mTOR network by PTEN.}

As mentioned above, PTEN is an important tumour suppressor and is frequently mutated in cancer (70). PTEN negatively regulates the PI3K/AKT/mTOR signalling cascade by dephosphorylating $\mathrm{PIP}_{3}$ to $\mathrm{PIP}_{2}$ (Figure 2). This dephosphorylation prevents the recruitment of AKT to the plasma membrane and inhibits downstream signalling (72). Deactivation mutations within PTEN lead to the sustained signalling of the PI3K/AKT/mTOR pathway $(70,73)$ via constitutive AKT activation. These mutations are less frequent in pHGG (5-15\% of cases) than in aHGG with loss of heterozygosity (LOH) observed in $<30 \%$ of cases $(19,74,75)$. However, PTEN promoter methylation, leading to decreased PTEN protein expression has been reported for pHGG (76). In addition, the allelic loss of PTEN in DIPG patients has been described (77). These provide a potential mechanism for the $\mathrm{PI3K} / \mathrm{AKT} / \mathrm{mTOR}$ pathway activation observed in $\mathrm{pHGG}$. Activation mutations within the PIK3CA catalytic subunit or the PIK3R1 regulatory subunit are observed in approximately $20 \%$ of all pHGG, a similar frequency to the percentage observed in the adult HGG population $(19,78)$. Such activation mutations could lead to an increase in autophagy through the inhibition of AKT phosphorylation, blocking mTOR and downstream signalling and allowing the transcription of autophagy related genes mediated by the fork-head transcription factor FOXO3a.

\section{Autophagy regulation via mTOR.}

The key regulator of autophagy mTOR, exists in one of two complexes that control multiple cellular processes (66). mTORC1 primarily regulates proliferation, protein synthesis and autophagy via growth factor signalling and nutrient and energy sensing. In contrast, mTORC2 primarily regulates metabolism and survival signalling. The formation of mTORC1 or 2 is determined by the upstream

This article is protected by copyright. All rights reserved. 
regulatory activators. These are the regulatory-associated protein of mTOR (RAPTOR) and the rapamycin-insensitive companion of mTOR (RICTOR) $(47,79)$. The depletion of mTORC2 and inhibition of AKT reduces the phosphorylation of the FOXO3a transcription factor allowing FOXO3a nuclear accumulation. This nuclear retention allows the FOXO3a-dependent transcription of numerous autophagy genes (80). It is important to note that mTORC2 regulation by the PI3K/AKT signalling is poorly understood in contrast to mTORC1, although the two may act competitively (8183). To date, mTORC2 is understood to be required for complete activation of AKT. AKT activation of mTORC1 may reduce the total available mTOR, consequently decreasing AKT phosphorylation and disrupting autophagy and cell survival signalling $(69,84)$. Compensatory signalling via mTORC2 when mTORC1 is abrogated could provide an important resistance mechanism to multiple mTOR inhibitors which have been evaluated to date $(69,85)$. In addition, the PI3K/AKT/mTOR signalling network is auto-regulated by several negative feedback loops, the dysregulation of which may also lead to constitutive activation of mTOR signalling (86).

Upstream of mTOR, AKT promotes mTOR signalling by phosphorylating tuberculosis sclerosis 2 (TSC2) at multiple residues, preventing TSC1/TSC2 complex formation and disabling Ras homology enriched in brain (Rheb) inhibition (60) (Figure 2). This stimulates mTORC1 complex formation and drives downstream signalling. The inactivation of TSC2 by AKT leads to an increase in mTORC2 activity, although the mechanism(s) of mTORC2 regulation by TSC1/TSC2 still remains unclear (87).

Post-translational modifications also have a direct role in autophagy regulation. Under nutrient rich conditions, G9A, a methyltransferase, associates with chromatin in the promoter region of ATGs. This prevents chromatin unwinding and transcription suppression. Following nutrient depletion, G9A dissociates from chromatin, permitting access to and transcription of the ATGs (88). This is supported by a proposed role for epigenetic regulation in the maintenance of the autophagy response. This is by the activation of AMPK and the subsequent downstream phosphorylation of FOXO3a, stabilising inducers of autophagy and lysosome components (89).

\section{The DNA Damage Response.}

The DNA Damage response (DDR) (Figure 2, shown in blue) primarily co-ordinates the recognition and repair of DNA lesions, in a highly orchestrated manner dependent on the nature of the damage and cell cycle phase at the time of DNA damage $(90,91)$. Repair processes include direct DNA repair, a single step process to remove agents bound to and distorting DNA strand(s). Single strand break repair is mediated by base excision repair (BER), nucleotide excision repair (NER), and

This article is protected by copyright. All rights reserved. 
mismatch repair (MMR). The repair of complex double strand breaks is conducted by single strand annealing (SSA), non-homologous end joining (NHEJ) or homologous recombination (HR). Multiple chemotherapeutics, as well as radiotherapy, induce widespread DNA damage via DNA-helix distorting reactive molecules, or the induction of direct DNA strand breaks (92). If left unresolved, this DNA damage in tandem with multiple stalled replication forks, signals catastrophic damage where the cell directs the induction of cell death pathways $(93,94)$. Three PIKK protein kinases are involved in directing the DDR, sensing damage and directing the repair process. AtaxiaTelangiesctasia mutated (ATM) and the DNA-dependent protein kinase (DNA-PK) respond to double strand breaks, while Ataxia telangiectasia and Rad3-related protein (ATR) is activated following single strand breaks. Aberrations in the DDR, including the inhibition or evasion of cell death pathways, are a major source of genomic instability and therapeutic resistance in almost all cancers (95).

There is complex interaction between the DDR, the tumour suppressor and "guardian of the genome" p53 and the process of autophagy (Figure 2). Following irradiation or chemotherapy, DNA damage is frequently observed in conjunction with autophagy, indicative of cross-talk between these networks (92). Following double strand DNA (dsDNA) breaks, ATM is activated, (via the MRN complex composed of Mre11, Nbs1 and Rad50), inhibiting mTORC1, mediated by AMPK. Downstream of ATM, TSC1/2 is activated driving the dephosphorylation of ATG13 and ULK1/2. Unphosphorylated ULK1/2 triggers the phosphorylation of both FIP200 and ATG13, leading to the formation and activation of the ULK1/2-ATG13-FIP200 complex. The protein complex translocates to the phagophore assembly site, initiating autophagy (96). In addition, ATM directly phosphorylates and stabilises p53, leading to the transcriptional regulation of autophagy by AMPK, itself forming a positive feedback loop with p53. Following ssDNA breaks, energy consuming PARP1 (Poly [ADPribose] polymerase 1 ) activation depletes cellular NAD+ ( $\beta$-nicotinamide adenine dinucleotide) and ATP, leading to significant energy depletion within the cell. This depletion activates AMPK and increases autophagy (97). The majority of dsDNA breaks are repaired by NHEJ, where sister chromatids are absent and unable to provide a repair template. Where DNA damage is catastrophic, DNA-PK mediates apoptosis via activation of $\mathrm{p53}$, suppression of pro-survival signalling and induction of pro-apoptotic gene expression (98-100). Autophagy is significantly induced upon irradiation and the knockdown of Beclin-1 leads to the disruption of Ku70 and Ku80 protein translocation from the nucleus, preventing recruitment of DNA-PK cs to dsDNA breaks and failure to mediate DNA repair (101). Clinical studies have shown that DNA-PK with glioma progression (102), poor clinical response and resistance to DNA damage inducing chemo- and radio-therapy regimens (103). DNA-PK ${ }_{C S}$ inhibition increased cell death in glioblastoma 
cells by the disruption of NHEJ and the sensitisation of exposed cells to telomerase inhibitors (104).

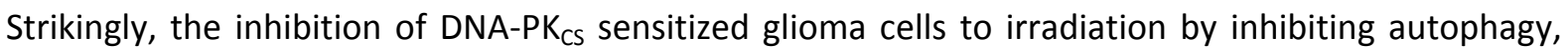
supporting the theory of autophagy-mediated irradiation resistance and the dependence of HGG cells on autophagy $(105,106)$.

Interestingly, autophagy is involved in the regulation and completion of the DDR by maintaining adequate pools of substrates required for DNA repair. An adequate supply of ATP is required for chromatin remodelling and relaxation of DNA, allowing DNA repair proteins to access lesions. During the DDR there is a cellular reduction of processes that have a high ATP demand, ensuring that the cell has sufficient energy reserves to enable DNA repair to occur. The level of NAD+ required for PARP1 function and maintenance of the cellular deoxyribonucleotide triphosphate pool for replication and repair is tightly regulated by autophagy. Where DNA damage is excessive or DNA repair is defective, fragmented chromosomes may be sequestered and degraded by autophagosomes. Upon DNA repair completion, autophagy regulates the sequestration and degradation of DNA damage response proteins, that are themselves substantial macromolecular complexes (107). A decrease in autophagic flux has been associated with the accumulation of DNA damage, either by the sustained increase in reactive oxygen species (ROS), or by the inhibition of the DDR protein complexes $(107,108)$. Considering the inherent genomic instability noted in PHGG and the drive for continuous cell division, modulating autophagy is of vital importance for the continued survival of pHGG cells.

Cross talk between autophagy and the DDR also regulates additional cellular processes. In particular, cell cycle progression is regulated by ATM and ATR which following activation, phosphorylate Checkpoint kinase-1 and Checkpoint Kinase-2 (CHK1/CHK2) preventing cell cycle progression. There is also transcriptional activation or repression of DDR genes via p53 and FOXO3a and, where repair cannot be completed effectively, initiation of programmed cell death via apoptosis, necrosis or autophagic cell death (109). A more complete understanding of the role the DDR plays in inducing and regulating autophagy (and vice versa) may be key to increasing pHGG sensitivity to chemo- and radio-therapy regimens. This could be via either inhibition of autophagy to circumvent pro-survival signalling and promoting apoptosis, or the hyper-activating autophagy towards inhibition of DNA damage response and promoting autophagic cell death (autosis) (110).

This article is protected by copyright. All rights reserved. 


\section{Epigenetic regulation and impact on the DDR and autophagy in pHGG.}

Exome sequencing has revealed that somatic histone mutations occur at high frequency in pHGG. It has been reported that up to $80 \%$ of brain stem (including DIPG) and $20 \%$ of non-brain stem pHGG present with somatic histone mutations and the presence of these correlate with patient prognosis $(111,112)$. The most frequent mutations are amino acid substitutions that lead to variants of core histones $\mathrm{H} 1$ and H3, at K27 (K27M) and less frequently, G34 (G34R/V) residues (Figure 2, shown in blue). Histone $\mathrm{H} 3$ plays an important role in replication, transcription and DNA repair, and frequently occurs in conjunction with TP53 mutations. It is reported that up to $83 \%$ of tumours with K27M mutations present TP53 co-mutations, 40\% harbour Platelet derived growth factor receptor $A$ (PDGFRA) co-mutation and 30\% show co mutation in Activin A Receptor Type 1 (ACVR1) (111,113). These data underline the substantive genetic instability inherent within these tumours.

DNA methylation plays a key role in gene expression, typically supressing transcription and mediating downstream signalling (89). A mechanism was proposed where histone deacetylases (HDACS) regulate chromosome stability via ATR and the DDR by the degradation of key proteins mediated by autophagy (114). The dysregulation of autophagy and associated regulatory pathways play a critical role in telomere stability (regulated by DNA-PK) in pHGG, which in turn are epigenetically regulated. In DIPG, ATRX-DAXX (Alpha Thalassemia/Mental Retardation Syndrome XLinked / Death Domain Associated protein) mutations occur in 9\% of cases, but of these, $100 \%$ cooccur with mutation of HIST1H3B. The H3.3-ATRX-DAXX complex plays an essential role in chromatin remodelling and subsequently in telomere maintenance and stability. The depletion of components within this protein complex leads to the destabilisation of telomeres and an increase in alternate lengthening of telomeres (ALT). These contribute to the substantial genomic instability and therapy resistance in these paediatric tumours (115). Together, these data describe the significant cross talk between DNA damage signalling, DDR and autophagy regulation in pHGG.

\section{Growth factor signalling and autophagy in pHGG.}

Growth factor signalling regulates multiple essential cellular processes including proliferation, differentiation and angiogenesis. Binding of growth factors to transmembrane receptors leads to downstream signalling and the regulation of gene expression. Vascular endothelial growth factor (VEGF) signalling is upregulated in $\mathrm{pHGG}$, increasing vasculature and permeability to meet the elevated energetic demands of the growing tumour (116). Strikingly, pHGG are some of the most vascularised tumours studied and consequently, anti-angiogenic therapies

This article is protected by copyright. All rights reserved. 
have generated much excitement. Bevacizumab, an anti-VEGF humanised monoclonal antibody therapy was viewed with great enthusiasm for the treatment of pHGG both as a single agent and as part of a combinatorial chemotherapeutic regimen. Bevacizumab acts to reduce tumour vasculature and increase vascular permeability by inhibiting VEGF. However, Bevacizumab alone, or in combination with chemotherapy in paediatric patients has not shown significant efficacy (117), despite being well tolerated (118-120). It has been suggested that resistance may be mediated by HIF1 $\alpha$ activated autophagy (121). As areas of the tumour become devascularised they become increasingly hypoxic and nutrient depleted. Within this microenvironment, autophagy is induced via HIF1 $\alpha /$ AMPK to maintain energy and substrate availability for the neoplastic cells (122). Therefore, the hyper-activation or the inhibition of autophagy, in addition to anti-angiogenic therapies (e.g. clonidine, chloroquine or rapalogues) could potentially overcome this autophagy mediated resistance, sensitizing pHGG to anti-VEGF therapeutics (122). Epidermal growth factor receptor (EGFR) mutations (including EGFRvIII) that lead to constitutive EGFR activation are one of the most frequent events in aHGG, but are rare in pHGG patients $(71,74)$. However, within the paediatric population, rather than EGFR mutations, there are instead frequent gene amplifications and consequently, the substantial overexpression of EGFR. Elevated EGFR protein expression is a poor prognostic factor for overall survival in pHGG patients $(123,124)$. Importantly, EGFR negatively regulates autophagy signalling by activating the PI3K/AKT/mTOR network, increasing RAS signalling, inhibiting of Beclin-1 and hyper-elevating intracellular glucose levels by the stabilisation of the sodium/glucose co-transporter SGLT1 $(125,126)$. Similarly, Platelet derived growth factor receptor (PDGFR) and signalling is a major driver and regulator of the pHGG phenotype. PDGFR is involved in differentiation, motility and is a major regulator of angiogenesis. Consequently, PDGFR dysregulation (including focal and copy number amplifications) as well as PDGFR protein activation is a major driver and frequently observed in pHGG $(71,74,77,127)$. Sequencing of DIPG patient tissue samples revealed PDGR amplification/gain of function, correlating with the most clinically aggressive tumours and leading to the hypothesis that PDGFR mutation is an early oncogenic driver event in DIPG tumours (128). To date, there has been limited success in clinical trials utilising RTK inhibitors. Aberrations of the receptor tyrosine kinases EGFR, PDGFR and VEGF in PHGG, and the induction of autophagy following RTK inhibition (129), suggest a possible therapeutic role for autophagy modulation in combination with these agents as potential treatments for pHGG (130-132).

This article is protected by copyright. All rights reserved. 


\section{Autophagy protein expression in pHGG patients.}

While there have been attempts to either promote or suppress autophagy as a therapeutic target in a range of cancers, the expression of key autophagy proteins has not been examined in tissue arrays from pHGG patients. This raised the interesting question as to whether there was robust expression of critical autophagy proteins in these tumours and if there was protein expression, whether they could be therapeutically targeted. We obtained a range of tissue microarrays (TMA) from 20 pHGG patients prior to treatment. These biopsy samples incorporated a diverse range of tumour locations (Figure 3a). With the exception of one tumour within the cerebellum, all of the others were supratentorial. From our small panel, most tumours originated within either the temporal lobe or the frontal lobe. Within this small cohort, $41 \%$ of the primary tumours were classified by neuropathologists as grade IV glioblastoma multiforme (GBM) using pre2016 WHO groupings. 47\% were histologically classified as grade III anaplastic astrocytoma while $11 \%$ were classified as grade III anaplastic oligodendroglioma. All patients were incorporated into the CNS 9204 clinical trial (133). Overall patient survival of this cohort was 357 days (Figure 3B) where patient survival varied from 57 days post-diagnosis up to 2625 days post-diagnosis where patient \#7 demonstrated a complete response following therapy (Figure 3c). Treatment naïve samples were stained for LC-3 A/B and Beclin-1 (Figure 3c). All stains were validated by a neuropathologist prior to quantification, and where protein scoring was quantified, a score of high positive, positive, low positive or negative was assigned for each patient core for each protein of interest (134). The autophagy marker Beclin-1 was selected for staining as this protein is essential for early autophagy induction and is a critical component of functional autophagosomes. The autophagy protein LC3 A/B is required for autophagosome membrane initiation and elongation (135) and is in general, considered the gold standard protein for the evaluation of autophagy. Strikingly, we note that there was significant, widespread positive staining for both Beclin-1 and LC3 A/B in many of these treatment naive patient biopsies. These data raised the interesting hypothesis that pHGG tumours have a requirement on a basal level of autophagy to provide sufficient energy and metabolic precursors for their continued growth and division. These observations and hypotheses are supported by published data that glial tumours exploit low level autophagy for nutrient cycling, whereas healthy brain tissues do not $(136,137)$. This proposed reliance on basal autophagy represents an important therapeutic vulnerability, and a possible route to sensitizing glioma cells to therapeutic interventions. It is of particular interest that basal autophagy is present in a diverse number of pHGG tumours. It is known from extensive genomic studies in pHGG tumours that these samples would be highly heterogeneous. This suggests that the therapeutic modulation of autophagy may be applicable to treat a wide range of paediatric glioma patients across many

This article is protected by copyright. All rights reserved. 
different sub-types. This is striking when one considers current approaches to examine the entire, highly heterogeneous genetic composition of pHGGs and from these studies, the further stratification and sub division of small patient populations. While this can identify unique tumour drivers and form a personalised medicine treatment platform(s), there are concerns regarding patient number and that if an appropriate treatment target were identified, if this agent would even be developed by the pharmaceutical industry (138). The general, widespread staining of key autophagy proteins suggests that targeting these, in combination with other standard therapeutics could offer significant promise to pHGG patients by circumventing such genetic heterogeneity.

We noted a striking observation in one particular patient TMA core sample set. First, in this patient, the HGG core was one of the few negative TMA cores for both Beclin-1 and LC3 A/B (Figure 4). This patient was incorporated into the UKCCSG/SIOP CNS 9204 trial. Within this trial, the patient underwent an aggressive chemotherapeutic regimen of; course 1, day 0 , vincristine (iv bolus) 1.5 $\mathrm{mg} / \mathrm{m}^{2}$, carboplatin (iv over $4 \mathrm{~h}$ ) $550 \mathrm{mg} / \mathrm{m}^{2}$; course 2, day 14 vincristine (iv bolus) $1.5 \mathrm{mg} / \mathrm{m}^{2}$, methotrexate $8000 \mathrm{mg} / \mathrm{m}^{2}$, folinic acid $\mathrm{mg}$ fixed dose; course 3, day 28, vincristine (iv bolus) 1.5 $\mathrm{mg} / \mathrm{m}^{2}$, cyclophosphamide $1500 \mathrm{mg} / \mathrm{m}^{2}$, mesna $1800 \mathrm{mg} / \mathrm{m}^{2}$; course 4 , day 42 , cisplatinum continuous infusion for $48 \mathrm{~h} 40 \mathrm{mg} / \mathrm{m}^{2}$ (138). Following disease recurrence, the relapsed tumour was biopsied allowing us to stain this relapsed tumour for both Beclin-1 and LC3 A/B (Figure 4). Significantly, in the relapsed treated tumour TMA, Beclin-1 and LC3 A/B protein expression was positive and in many regions, highly positive. Critically, both the original biopsy core and relapse tumour cores were within the same TMA and stained together for each protein. These data are in line with current literature where radio- and chemo-therapy exposure (including cisplatin) has been shown to induce autophagy $(15,139,140)$, mediated by the generation of ROS, endoplasmic reticulum stress, hypoxia, DNA damage and inflammatory signalling. These data suggest that an increase in autophagy presents an important mechanism of resistance and we propose this could be therapeutically targetable in pHGG. In addition to sensitizing therapeutics, abrogation or hyperactivation of autophagy may help to minimise tumour regrowth and prevent malignant progression. Importantly, these data raised the hypothesis that agents that modulate autophagy could be of significant interest in the treatment and potential management of relapsed disease, where at present, there are highly limited therapeutic options. Considering the dire clinical prognosis following disease relapse, this is of compelling interest to the field.

Autophagy has been proposed as a 'cell-fate decision maker'. These decisions may direct tumour suppression or promotion although each are context and stimuli dependent. The tumour micro-environment and cellular context can also direct autophagy-dependent cell fate (141). The appropriate abrogation or promotion of autophagy may drive or rescue programmed cell death

This article is protected by copyright. All rights reserved. 
mechanisms by reprogramming signalling networks and sensitizing tumours to chemo- and radiotherapy (142-144). These are compelling in pHGG patients where chemo- or radio-therapy sensitisation could have a profound impact on patient prognosis.

\section{Autophagy-mediated chemo- and radiotherapy resistance.}

As considered above, autophagy has been shown to contribute to chemo- and radio-therapy resistance. Indeed, the protein expression differences in essential autophagy proteins between treatment naïve biopsy samples and relapse biopsy samples following an aggressive multi-drug treatment regimen is compelling, albeit from limited patient numbers (Figure 4). These types of therapy have been shown to induce cryoprotective autophagy by promoting the transcription of autophagy genes including Beclin-1 and various ATGs, as well as inducing the sustained inhibition of AKT/mTOR and AMPK (145). Furthermore, non-DNA targeting chemotherapies used to treat pHGG may stimulate autophagy by increasing ROS production and hypoxia inducing chemotherapies for pHGG patients may stimulate AMPK and HIF-1 $\alpha$ activation, impacting autophagy, driving resistance.

The RAS/RAF/MEK/Erk signalling pathway relays signals from the extracellular environment to the nucleus, and is involved in cell proliferation, differentiation and survival (146). The BRAFV600E mutation results in a truncated BRAF protein, allowing monomeric BRAF to activate signalling, rather than requiring dimer formation. This mutation increases signalling through the MAPK/Erk signalling cascade, driving tumour growth. BRAFV600E has been reported in approximately $20 \%$ of all pHGG compared to $<10 \%$ in pLGG and approximately $5 \%$ in aHGG (147). BRAFV600E mutant cells show elevated autophagy and are resistant to multiple therapeutic interventions, including to the BRAF inhibitor Vemurafenib (148). However, following autophagy inhibition, these tumours are sensitized to RAF or PI3K inhibitors (149).

\section{Clinical application of autophagy modulation in pHGG.}

A major focus for targeting autophagy has been inhibition of mTOR with rapamycin or rapalogs including sirolimus, evirolimus and temsirolimus. These approaches and trials are summarized in table 1. Rapamycin and rapalogs have high specificity for mTORC1 where they bind to and induce a conformational change in the mTORC1 catalytic ATP-binding site. This change prevents the phosphorylation of mTOR and ablates downstream signalling (150). Phase I trials with rapamycin (sirolimus), in combination with additional chemotherapeutics were well tolerated in pHGG patients, but demonstrated minimal anti-tumour efficacy (151). Additional clinical trials with

This article is protected by copyright. All rights reserved. 
rapalogs are in progress and include sirolimus alone (NCT01331135), rapamycin and HIF1 $\alpha$ inhibitor Irinotecan (NCT01282697), and the oral administration of sirolimus, cyclophosphamide and topotecan (NCT01670175). Three clinical trials including Evirolimus are currently in progress for paediatric patients, including a feasibility study for treatment based on tumour biopsy (NCT02015728), non-randomized phase I trials for refractory and recurrent brain tumours (NCT00187174, NCT03387020) and NCT02233049, a randomised phase II trial recruiting DIPG patients where treatment regimens are directed against EGFR overexpression, PTEN loss or combination mutations. Temsirolimus (a rapalog) has been well tolerated in phase I (152) and phase II (153) clinical trials, where disease stabilisation was reported in the phase II trial. However, there was no significant treatment efficacy and the trial was halted. A phase I trial (NCT01614795) of combined temsirolimus and cixutumumab also reported good patient tolerance, although a limited treatment response in recurrent brain tumours was noted (154). A further phase I trial (NCT00880282) has been completed recently with results expected soon. A MATCH trial with mTOR/DNA-PK dual inhibitor is currently recruiting (NCT03213678). Taken together these results should be viewed positively, with temsirolimus being well tolerated over long term use, and could therefore be a promising candidate for future combinatorial approaches. The limited anti-tumour effect of rapamycin and rapalogs may be explained by their specificity for mTORC1, and not mTORC2, permitting compensatory resistance signalling. This may be by the hyper-activation of AKT via mTORC1 inactivation and positive feedback signalling though uninhibited mTORC2. Additionally, aberrant p53 signalling and PTEN co-deletion events may lead to constitutively activated mTORC2 signalling (80), increasing acetylation of FOXO3a, stimulating c-Myc signalling and mediating glycolysis (80). Only recently discovered, mTORC2 signalling is highly complex and plays an important role in chemotherapeutic resistance (155). There is great interest in developing efficient, specific, dual targeting inhibitors of mTORC1 and mTORC2, including second generation ATP-competitive mTOR inhibitors. The dual mTORC1 and mTORC2 inhibitor, AZD2014, with combined chemotherapeutics, is currently in proof of concept studies for relapsed and refractory tumours (NCT02813135), although to date, their clinical efficacy remains to be proven.

Activation of the PI3K signalling network, by targeting multiple effector and activator signalling nodes, is an attractive therapeutic target. There has been significant research efforts invested in characterising and progressing PI3K inhibitors into clinical trials (156). Over 30 agents covering PI3K Class 1 pan specific inhibitors (including Pictilisib, Buparlisib, Pilaralisib) and PI3K isoform-specific inhibitors (including Idelalisib) have entered pHGG clinical trials $(68,86)$.

This article is protected by copyright. All rights reserved. 
Recent data from Levy et al show in vitro and ex vivo evidence that inhibition of autophagy in BRAFV600 mutant brain tumours overcomes multiple mechanisms of resistance to kinase inhibitors. Although the sample size is small, and proof of concept studies are yet to be carried out in vivo, this is positive evidence of the role autophagy plays in mediating chemotherapy resistance (24). Additional clinical trials targeting BRAFV600E mutations include Phase I clinical trials with Dabrafenib (NCT01677741) and Vemurafenib (NCT01748149), and an additional Phase II trial with Dabrafenib and the MEK 1/2 inhibitor Trametinib (NCT02684058) continue to recruit patients. Phase I and Phase II trials targeting RTK inhibitors include combined Bevacizumab with Lapatinib (NCT00883688); GDC0084 for DIPG and midline glioma (NCT03696355); PCT299, a VEGF inhibitor (NCT01158300) and Erlotinib in combination with temozolomide (NCT00077454). A Phase 1 trial targeting MDMx/MDM2 inhibition, rescuing wild-type p53 stabilisation with ALRN-6924, (NCT03654716) has also been initiated.

It is less complicated to inhibit activation signalling than it is to recover loss-of-function in diverse, complex signalling networks. Despite this significant research investment, there has been only a modest return, with resistance and toxicity continuing to be the mainstay of trial failure (157). Frequently, targeted inhibitors are cytostatic rather than cytotoxic, both in vitro and in vivo. A combinatorial treatment approach, combining upstream inhibitors with chemotherapeutics targeting additional signalling nodes, may provide a mechanism of complete pathway abrogation and more effective pHGG treatment regimes.

\section{Concluding remarks.}

Autophagy is a complex process and there is significant cross talk between networks that regulate, or are regulated by, autophagy signalling. These include the PI3K, p53 and DDR. Autophagy should also be considered both a transient and dynamic process where the timing of the application of therapeutic intervention(s) requires careful consideration. The exact role autophagy plays in pHGG survival, proliferation and therapeutic resistance continues to be widely debated. The pathway is intricate, with multiple regulatory and inhibitory factors, mediating multiple pro- and anti- cell death mechanisms. This complexity is frequently compounded by multiple driver mutations within these regulatory pathways, which accumulate over time as tumours grow and develop, react to metabolic constraints, respond to the tumour micro-environment and adapt following chemoand radio-therapy cycles. These mutations do not occur in isolation, and it is the accumulation of these mutations which give rise to the extensive tumour heterogeneity and diverse mechanisms of therapeutic evasion displayed by pHGG. Perhaps the most significant consideration is the 
appropriate application of radio- and chemo-therapy which may drive an increasingly aggressive, adaptive and resistant phenotype characterized by autophagy deregulation (Figure 4).

The search for efficacious clinical candidates for the treatment of pHGG remains critical. This can incorporate validating novel therapeutic candidates, repurposing clinically available molecules, or combinatorial chemotherapies to sensitize these tumours to radio- and chemo-therapy. Any potential therapy must minimise adverse toxicity and maintain efficacy over long term use. Therapeutic design must increasingly take into account the dynamic heterogeneity of pHGG, mechanisms of resistance and the complexity of delivering therapeutics to these tumours at an effective concentration. As discussed by Jones et al, pHGG clinical trials are complex, compounded by limited patient numbers, require multi-centre cooperation and extended time scales to achieve meaningful recruitment and statistical significance (20). Large groups with an inherent tumour heterogeneity may mask any positive impact of a smaller sub-group contained within it. In addition, a small group may never achieve significant patient numbers for downstream analysis and statistical scrutiny. The complexity of inclusion criteria within clinical trials must also be considered. Patients entering clinical trials have typically been exposed to, and failed to respond to, a variety of aggressive treatments. The effect of pre-exposure on tumour malignancy and therapy resistance should be considered within the clinical trial design. Profiling patients to determine genetic and epigenetic expression is likely to be the key to designing and applying clinically relevant therapeutics during the development of adaptive clinical trials. Here we describe the importance of autophagy within pHGG, where the modulation of autophagy offers scope for more efficacious, better tolerated, and tailored therapeutic options for young patients and warrants extensive further study.

This article is protected by copyright. All rights reserved. 


\section{References}

39. Alers S, Löffler AS, Wesselborg S, Stork B. Role of AMPK-mTOR-Ulk1/2 in the regulation of autophagy: cross talk, shortcuts, and feedbacks. Mol Cell Biol. 2012 Jan;32(1):2-11.

88. Artal-Martinez de Narvajas A, Gomez TS, Zhang J-S, Mann AO, Taoda Y, Gorman JA, et al. Epigenetic Regulation of Autophagy by the Methyltransferase G9a. Mol Cell Biol. 2013;33(20):3983-93.

150. Ballou LM, Lin RZ. Rapamycin and mTOR kinase inhibitors. J Chem Biol. 2008 Nov;1(1-4):27-36.

146. Basto D, Trovisco V, Lopes JM, Martins A, Pardal F, Soares P, et al. Mutation analysis of B-RAF gene in human gliomas. Acta Neuropathol. 2005 Feb;109(2):207-10.

124. Bax DA, Gaspar N, Little SE, Marshall L, Perryman L, Regairaz M, et al. EGFRvIII Deletion Mutations in Pediatric High-Grade Glioma and Response to Targeted Therapy in Pediatric Glioma Cell Lines. Clin Cancer Res. 2009 Sep;15(18):5753-61.

1. Bax DA, Little SE, Gaspar N, Perryman L, Marshall L, Viana-Pereira M, et al. Molecular and phenotypic characterisation of paediatric glioma cell lines as models for preclinical drug development. PLoS One. 2009 Jan;4(4):e5209.

127. Bax DA, Mackay A, Little SE, Carvalho D, Viana-Pereira M, Tamber N, et al. A Distinct Spectrum of Copy Number Aberrations in Pediatric High-Grade Gliomas. Clin Cancer Res. 2010 Jul;16(13):3368-77.

63. Beagle B, Fruman DA. A Lipid Kinase Cousin Cooperates to Promote Cancer. Cancer Cell. 2011;19(6):693-5.

102. Becher OJ, Peterson KM, Khatua S, Santi MR, MacDonald TJ. IGFBP2 is overexpressed by pediatric malignant astrocytomas and induces the repair enzyme DNA-PK. In: Journal of Child Neurology. 2008. p. 1205-13.

31. Bednarczyk M, Zmarzły N, Grabarek B, Mazurek U, Muc-Wierzgoń M. Genes involved in the regulation of different types of autophagy and their participation in cancer pathogenesis. Oncotarget. 2018 Sep;9(76):34413-28.

57. Bell D, Berchuck A, Birrer M, Chien J, Cramer DW, Dao F, et al. Integrated genomic analyses of ovarian carcinoma. Nature. 2011 Jun;474(7353):609-15.

This article is protected by copyright. All rights reserved. 
144. Booth LA, Tavallai S, Hamed HA, Cruickshanks N, Dent P. The role of cell signalling in the crosstalk between autophagy and apoptosis. Cell Signal. 2014 Mar;26(3):549-55. 144

83. Cao Y, Luo Y, Zou J, Ouyang J, Cai Z, Zeng X, et al. Autophagy and its role in gastric cancer. Clin Chim Acta [Internet]. 2019 Feb 22 [cited 2018 Dec 12];489:10-20.

113. Castel D, Philippe C, Calmon R, Le Dret L, Truffaux N, Boddaert N, et al. Histone H3F3A and HIST1H3B K27M mutations define two subgroups of diffuse intrinsic pontine gliomas with different prognosis and phenotypes. Acta Neuropathol. 2015 Dec;130(6):815-27.

70. Chalhoub N, Baker SJ. PTEN and the PI3-kinase pathway in cancer. Annu Rev Pathol. 2009;4:127-50.

47. Cheong $\mathrm{H}$, Lindsten $\mathrm{T}, \mathrm{Wu}$ J, Lu C, Thompson CB. Ammonia-induced autophagy is independent of ULK1/ULK2 kinases. Proc Natl Acad Sci. 2011 Jul;108(27):11121-6.

7. Cohen KJ, Pollack IF, Zhou T, Buxton A, Holmes EJ, Burger PC, et al. Temozolomide in the treatment of high-grade gliomas in children: a report from the Children's Oncology Group. Neuro Oncol [Internet]. 2011 Mar 1 [cited 2018 Jun 4];13(3):317-23.

56. Comprehensive genomic characterization defines human glioblastoma genes and core pathways. Vol. 455, Nature. p. 1061-8.

33. Cuervo AM, Wong E. Chaperone-mediated autophagy: roles in disease and aging. Cell Res. 2014 Jan;24(1):92-104.

73. Cully M, You H, Levine AJ, Mak TW. Beyond PTEN mutations: the PI3K pathway as an integrator of multiple inputs during tumorigenesis. Nat Rev Cancer. 2006 Mar;6(3):184-92.

96. Czarny P, Pawlowska E, Bialkowska-Warzecha J, Kaarniranta K, Blasiak J. No Title. 2015 Jan;16(2).

108. Czarny P, Pawlowska E, Bialkowska-Warzecha J, Kaarniranta K, Blasiak J. Autophagy in DNA damage response. Int J Mol Sci. 2015 Jan;16(2):2641-62.

147. Dahiya S, Emnett RJ, Haydon DH, Leonard JR, Phillips JJ, Perry A, et al. BRAF-V600E mutation in pediatric and adult glioblastoma. Neuro Oncol. 2014 Feb;16(2):318-9.

105. Daido S, Yamamoto A, Fujiwara K, Sawaya R, Kondo S, Kondo Y. Inhibition of the DNADependent Protein Kinase Catalytic Subunit Radiosensitizes Malignant Glioma Cells by Inducing Autophagy. Cancer Res. 2005 May;65(10):4368-75.

This article is protected by copyright. All rights reserved. 
75. Diaz AK, Baker SJ. The Genetic Signatures of Pediatric High-Grade Glioma: No Longer a One-Act Play. Semin Radiat Oncol. 2014 Oct;24(4):240-7.

18. Donson AM, Addo-Yobo SO, Handler MH, Gore L, Foreman NK. MGMT promoter methylation correlates with survival benefit and sensitivity to temozolomide in pediatric glioblastoma. Pediatr Blood Cancer. 2007 Apr;48(4):403-7.

107. Eliopoulos AG, Havaki S, Gorgoulis VG. DNA Damage Response and Autophagy: A Meaningful Partnership. Front Genet. 2016;7:204.

3. Fangusaro J. Pediatric high grade glioma: a review and update on tumor clinical characteristics and biology. Front Oncol. 2012 Jan;2:105.

49. Feng D, Amgalan D, Singh R, Wei J, Wen J, Wei TP, et al. SNAP23 regulates BAX-dependent adipocyte programmed cell death independently of canonical macroautophagy. J Clin Invest [Internet]. 2018 Aug 31 [cited 2018 Dec 13];128(9):3941-56.

28. Feng $\mathrm{Y}, \mathrm{He} \mathrm{D}, \mathrm{Yao} Z$, Klionsky DJ. The machinery of macroautophagy. Cell Res. 2014 Jan;24(1):24-41.

142. Fitzwalter BE, Thorburn A. Recent insights into cell death and autophagy. FEBS J. 2015 Nov;282(22):4279-88.

154. Fouladi M, Perentesis JP, Wagner LM, Vinks AA, Reid JM, Ahern C, et al. A Phase I Study of Cixutumumab (IMC-A12) in Combination with Temsirolimus (CCl-779) in Children with Recurrent Solid Tumors: A Children's Oncology Group Phase I Consortium Report. Clin Cancer Res. 2015 Apr;21(7):1558-65.

84. Fruman DA, Rommel C. PI3K and cancer: lessons, challenges and opportunities. Nat Rev Drug Discov. 2014 Jan;13(2):140-56.

44. Füllgrabe J, Klionsky DJ, Joseph B. The return of the nucleus: transcriptional and epigenetic control of autophagy. Nat Rev Mol Cell Biol. 2013 Dec;15(1):65-74.

78. Gallia GL, Rand V, Siu IM, Eberhart CG, James CD, Marie SK, et al. PIK3CA gene mutations in pediatric and adult glioblastoma multiforme. Vol. 4, Mol.Cancer Res. p. 709-14.

153. Geoerger B, Kieran MW, Grupp S, Perek D, Clancy J, Krygowski M, et al. Phase II trial of temsirolimus in children with high-grade glioma, neuroblastoma and rhabdomyosarcoma. Eur $\mathrm{J}$ Cancer. 2012 Jan;48(2):253-62.

137. Giatromanolaki A, Sivridis E, Mitrakas A, Kalamida D, Zois CE, Haider S, et al. Autophagy and

This article is protected by copyright. All rights reserved. 
Iysosomal related protein expression patterns in human glioblastoma. Cancer Biol Ther. 2014 Nov;15(11):1468-78.

5. Gottardo NG, Gajjar A. Chemotherapy for malignant brain tumors of childhood. J Child Neurol [Internet]. 2008 Oct [cited 2018 Jun 4];23(10):1149-59.

143. Green DR, Levine B. To Be or Not to Be? How Selective Autophagy and Cell Death Govern Cell Fate. Cell. 2014 Mar;157(1):65-75.

133. Grundy RG, Wilne SH, Robinson KJ, Ironside JW, Cox T, Chong WK, et al. Primary postoperative chemotherapy without radiotherapy for treatment of brain tumours other than ependymoma in children under 3 years: Results of the first UKCCSG/SIOP CNS 9204 trial. Eur J Cancer. 2010;

104. Gurung RL, Lim HK, Venkatesan S, Lee PSW, Hande MP. Targeting DNA-PKcs and telomerase in brain tumour cells. Mol Cancer. 2014;13(1).

118. Gururangan S, Chi SN, Young Poussaint T, Onar-Thomas A, Gilbertson RJ, Vajapeyam S, et al. Lack of Efficacy of Bevacizumab Plus Irinotecan in Children With Recurrent Malignant Glioma and Diffuse Brainstem Glioma: A Pediatric Brain Tumor Consortium Study. J Clin Oncol. 2010 Jun;28(18):3069-75.

91. Hakem R. DNA-damage repair; the good, the bad, and the ugly. EMBO J. 2008 Feb;27(4):589605.

95. Halazonetis TD, Gorgoulis VG, Bartek J. An Oncogene-Induced DNA Damage Model for Cancer Development. Science (80- ). 2008 Mar;319(5868):1352-5.

58. Hammerman PS, Lawrence MS, Voet D, Jing R, Cibulskis K, Sivachenko A, et al. Comprehensive genomic characterization of squamous cell lung cancers. Nature. 2012 Sep;489(7417):519-25.

14. Hargrave D. Diffuse brainstem gliomas in children: should we or shouldn't we biopsy? Br J Neurosurg. 2008 Jan;22(5):624-624.

139. Harhaji-Trajkovic L, Vilimanovich U, Kravic-Stevovic T, Bumbasirevic V, Trajkovic V. AMPKmediated autophagy inhibits apoptosis in cisplatin-treated tumour cells. J Cell Mol Med. 2009 Sep;13(9b):3644-54.

109. Harper JW, Elledge SJ. The DNA Damage Response: Ten Years After. Mol Cell. 2007;28(5):73945.

135. He R, Peng J, Yuan P, Xu F, Wei W. Divergent roles of BECN1 in LC3 lipidation and autophagosomal function. Autophagy. 2015;11(5):740-7.

This article is protected by copyright. All rights reserved. 
17. Hegi ME, Diserens A-C, Gorlia T, Hamou M-F, de Tribolet N, Weller M, et al. MGMT Gene Silencing and Benefit from Temozolomide in Glioblastoma. N Engl J Med [Internet]. 2005 Mar 10 [cited 2018 Mar 22];352(10):997-1003.

156. Hennessy BT, Smith DL, Ram PT, Lu Y, Mills GB. Exploiting the PI3K/AKT Pathway for Cancer Drug Discovery. Nat Rev Drug Discov. 2005 Dec;4(12):988-1004.

98. Hill R, Madureira PA, Waisman DM, Lee PWK. DNA-PKCS binding to $p 53$ on the p21WAF1/CIP1 promoter blocks transcription resulting in cell death. Oncotarget. 2011 Dec;2(12):1094-108.

119. Hoffman LM, Geller J, Leach J, Boue D, Drissi R, Chen L, et al. TR-14 * A FEASIBILITY AND RANDOMIZED PHASE II STUDY OF VORINOSTAT, BEVACIZUMAB, OR TEMOZOLOMIDE DURING RADIATION FOLLOWED BY MAINTENANCE CHEMOTHERAPY IN NEWLY-DIAGNOSED PEDIATRIC HIGH-GRADE GLIOMA: CHILDREN'S ONCOLOGY GROUP STUDY ACNS0822. Neuro Oncol. 2015 Jun;17(suppl 3):iii39-iii40.

50. Hou W, Han J, Lu C, Goldstein LA, Rabinowich H. Autophagic degradation of active caspase-8. Autophagy [Internet]. 2010 Oct 27 [cited 2018 Dec 13];6(7):891-900.

122. Hu Y-L, DeLay M, Jahangiri A, Molinaro AM, Rose SD, Carbonell WS, et al. Hypoxia-Induced Autophagy Promotes Tumor Cell Survival and Adaptation to Antiangiogenic Treatment in Glioblastoma. Cancer Res. 2012 Apr;72(7):1773-83.

29. Huang $Q$, Zhan L, Cao H, Li J, Lyu Y, Guo X, et al. Increased mitochondrial fission promotes autophagy and hepatocellular carcinoma cell survival through the ROS-modulated coordinated regulation of the NFKB and TP53 pathways. Autophagy. 2016 Apr;1-16.

90. Jackson SP, Bartek J. The DNA-damage response in human biology and disease. Nature. 2010;461(7267):1071-8.

136. Jennewein L, Ronellenfitsch MW, Antonietti P, llina EI, Jung J, Stadel D, et al. Diagnostic and clinical relevance of the autophago-lysosomal network in human gliomas. Oncotarget. 2016 Apr;7(15):20016-32.

20. Jones C, Baker SJ. Unique genetic and epigenetic mechanisms driving paediatric diffuse highgrade glioma. Nat Rev Cancer. 2014 Oct;14(10).

4. Jones C, Karajannis MA, Jones DTW, Kieran MW, Monje M, Baker SJ, et al. Pediatric high-grade glioma: biologically and clinically in need of new thinking. Neuro Oncol. 2016 Jun;now101.

10. Jones C, Perryman L, Hargrave D. Paediatric and adult malignant glioma: close relatives or

This article is protected by copyright. All rights reserved. 
distant cousins? Nat Rev Clin Oncol. 2012 Jul;9(7):400-13.

60. Jung $\mathrm{CH}$, Ro S-H, Cao J, Otto NM, Kim D-H. mTOR regulation of autophagy. FEBS Lett. 2010 Apr;584(7):1287-95.

125. Jutten B, Rouschop KMA. EGFR signaling and autophagy dependence for growth, survival, and therapy resistance. Cell Cycle. 2014;13(1):42-51.

8. Karajannis M, Allen JC, Newcomb EW. Treatment of pediatric brain tumors. J Cell Physiol. 2008 Dec;217(3):584-9.

30. Kaur J, Debnath J. Autophagy at the crossroads of catabolism and anabolism. Nat Rev Mol Cell Biol. 2015 Jul;16(8):461-72.

34. Kaushik S, Cuervo AM. Chaperone-mediated autophagy: a unique way to enter the lysosome world. Trends Cell Biol. 2012 Aug;22(8):407-17.

45. Kepp O, Galluzzi L, Lipinski M, Yuan J, Kroemer G. Cell death assays for drug discovery. Nat Rev Drug Discov. 2011 Mar;10(3):221-37.

53. Kessel D, Reiners JJ. Promotion of Proapoptotic Signals by Lysosomal Photodamage. Photochem Photobiol [Internet]. 2015 Jul [cited 2018 Dec 13];91(4):931-6.

54. Kessel DH, Price M, Reiners, Jr. JJ. ATG7 deficiency suppresses apoptosis and cell death induced by lysosomal photodamage. Autophagy [Internet]. 2012 Sep 14 [cited 2018 Dec 13];8(9):133341.

46. Klionsky DJ, Abeliovich H, Agostinis P, Agrawal DK, Aliev G, Askew DS, et al. Guidelines for the use and interpretation of assays for monitoring autophagy in higher eukaryotes. Autophagy. 2008;4(2):151.

15. Koukourakis MI, Mitrakas AG, Giatromanolaki A. Therapeutic interactions of autophagy with radiation and temozolomide in glioblastoma: evidence and issues to resolve. Br J Cancer. 2016 Mar;114(5):485-96.

42. Lambelet M, Terra LF, Fukaya M, Meyerovich K, Labriola L, Cardozo AK, et al. Dysfunctional autophagy following exposure to pro-inflammatory cytokines contributes to pancreatic $\beta$-cell apoptosis article. Cell Death Dis. 2018;9(2).

69. Laplante M, Sabatini DM. mTOR Signaling in Growth Control and Disease. Cell. 2012 Apr;149(2):274-93.

This article is protected by copyright. All rights reserved. 
67. Lempiäinen $\mathrm{H}$, Halazonetis TD. Emerging common themes in regulation of PIKKs and PI3Ks. EMBO J. 2009 Oct;28(20):3067-73.

24. Levy JMM, Thorburn A. Modulation of pediatric brain tumor autophagy and chemosensitivity. J Neurooncol. 2012 Jan;106(2):281-90.

149. Levy JMM, Zahedi S, Griesinger AM, Morin A, Davies KD, Aisner DL, et al. Autophagy inhibition overcomes multiple mechanisms of resistance to BRAF inhibition in brain tumors. Elife. 2017;6.

32. Li W, Li J, Bao J. Microautophagy: lesser-known self-eating. Cell Mol Life Sci. 2012 Apr;69(7):1125-36.

123. Liang M-L, Ma J, Ho M, Solomon L, Bouffet E, Rutka JT, et al. Tyrosine kinase expression in pediatric high grade astrocytoma. J Neurooncol. 2008 May;87(3):247-53.

101. Liu C, He W, Jin M, Li H, Xu H, Liu H, et al. Blockage of Autophagy in C6 Glioma Cells Enhanced Radiosensitivity Possibly by Attenuating DNA-PK-Dependent DSB Due to Limited Ku Nuclear Translocation and DNA Binding. Curr Mol Med. 2015;15(7):663-73.

68. Liu P, Cheng H, Roberts TM, Zhao JJ. Targeting the phosphoinositide 3-kinase pathway in cancer. Nat Rev Drug Discov. 2009 Aug;8(8):627-44.

110. Liu Y, Levine B. Autosis and autophagic cell death: the dark side of autophagy. Cell Death Differ [Internet]. 2015 Mar 26 [cited 2018 Mar 22];22(3):367-76.

115. Long W, Yi Y, Chen S, Cao Q, Zhao W, Liu Q. Potential new therapies for pediatric diffuse intrinsic pontine glioma. Vol. 8, Frontiers in Pharmacology. 2017.

9. MacDonald TJ, Aguilera D, Kramm CM. Treatment of high-grade glioma in children and adolescents. Neuro Oncol. 2011 Oct;13(10):1049-58.

22. Mackay A, Burford A, Carvalho D, Izquierdo E, Fazal-Salom J, Taylor KR, et al. Integrated Molecular Meta-Analysis of 1,000 Pediatric High-Grade and Diffuse Intrinsic Pontine Glioma. Cancer Cell [Internet]. 2017 Oct 9 [cited 2018 Dec 12];32(4):520-537.e5.

48. Mariño G, Niso-Santano M, Baehrecke EH, Kroemer G. Self-consumption: the interplay of autophagy and apoptosis. Nat Rev Mol Cell Biol. 2014 Jan;15(2):81-94.

66. Martini M, De Santis MC, Braccini L, Gulluni F, Hirsch E. PI3K/AKT signaling pathway and cancer: an updated review. Ann Med. 2014 Sep;46(6):372-83.

40. Mathiassen SG, De Zio D, Cecconi F. Autophagy and the Cell Cycle: A Complex Landscape. Front

This article is protected by copyright. All rights reserved. 
Oncol. 2017;7.

132. Mellinghoff IK, Schultz N, Mischel PS, Cloughesy TF. Will Kinase Inhibitors Make it as Glioblastoma Drugs? In: Current topics in microbiology and immunology. 2011. p. 135-69.

141. Mora R, Régnier-Vigouroux A. Autophagy-driven cell fate decision maker: activated microglia induce specific death of glioma cells by a blockade of basal autophagic flux and secondary apoptosis/necrosis. Autophagy. 2009 Apr;5(3):419-21.

151. Morgenstern DA, Marzouki M, Bartels U, Irwin MS, Sholler GLS, Gammon J, et al. Phase I study of vinblastine and sirolimus in pediatric patients with recurrent or refractory solid tumors. Pediatr Blood Cancer. 2014 Jan;61(1):128-33.

82. Mossmann D, Park S, Hall MN. mTOR signalling and cellular metabolism are mutual determinants in cancer. Nat Rev Cancer [Internet]. 2018 Dec 13 [cited 2018 Dec 12];18(12):74457.

76. Mueller S, Phillips J, Onar-Thomas A, Romero E, Zheng S, Wiencke JK, et al. PTEN promoter methylation and activation of the PI3K/Akt/mTOR pathway in pediatric gliomas and influence on clinical outcome. Neuro Oncol. 2012 Sep;14(9):1146-52.

59. Mulcahy Levy JM, Foreman NK, Thorburn A. Using BRAF(V600E) as a marker of autophagy dependence in pediatric brain tumors. Autophagy. 2014;10(11):2077-8.

97. Muñoz-Gámez JA, Rodríguez-Vargas JM, Quiles-Pérez R, Aguilar-Quesada R, Martín-Oliva D, De Murcia G, et al. PARP-1 is involved in autophagy induced by DNA damage. Autophagy. 2009;5(1):61-74.

117. Narayana A, Kunnakkat S, Chacko-Mathew J, Gardner S, Karajannis M, Raza S, et al. Bevacizumab in recurrent high-grade pediatric gliomas. Neuro Oncol. 2010 Sep;12(9):985-90.

52. Nezis IP, Shravage B V, Sagona AP, Johansen T, Baehrecke EH, Stenmark H. Autophagy as a trigger for cell death: autophagic degradation of inhibitor of apoptosis dBruce controls DNA fragmentation during late oogenesis in Drosophila. Autophagy [Internet]. 2010 Nov [cited 2018 Dec 13];6(8):1214-5.

51. Nezis IP, Shravage B V., Sagona AP, Lamark T, Bjørkøy G, Johansen T, et al. Autophagic degradation of dBruce controls DNA fragmentation in nurse cells during late Drosophila melanogaster oogenesis. J Cell Biol [Internet]. 2010 Aug 23 [cited 2018 Dec 13];190(4):523-31.

116. Norden AD, Drappatz J, Wen PY. Antiangiogenic therapies for high-grade glioma. Nat Rev

This article is protected by copyright. All rights reserved. 
Neurol. 2009 Nov;5(11):610-20.

80. Oh WJ, Jacinto E. mTOR complex 2 signaling and functions. Vol. 10, Cell Cycle. 2011. p. 2305-16.

2. Ostrom QT, Gittleman H, Liao P, Rouse C, Chen Y, Dowling J, et al. CBTRUS statistical report: primary brain and central nervous system tumors diagnosed in the United States in 2007-2011. Neuro Oncol. 2014 Oct;16 Suppl 4:iv1-63.

41. Papandreou I, Lim AL, Laderoute K, Denko NC. Hypoxia signals autophagy in tumor cells via AMPK activity, independent of HIF-1, BNIP3, and BNIP3L. Cell Death Differ. 2008;15(10):157281.

120. Parekh C, Jubran R, Erdreich-Epstein A, Panigrahy A, Bluml S, Finlay J, et al. Treatment of children with recurrent high grade gliomas with a bevacizumab containing regimen. $J$ Neurooncol. 2011 Jul;103(3):673-80.

71. Paugh BS, Qu C, Jones C, Liu Z, Adamowicz-Brice M, Zhang J, et al. Integrated Molecular Genetic Profiling of Pediatric High-Grade Gliomas Reveals Key Differences With the Adult Disease. J Clin Oncol. 2010 Jun;28(18):3061-8.

145. Pawlowska E, Szczepanska J, Szatkowska M, Blasiak J. An Interplay between Senescence, Apoptosis and Autophagy in Glioblastoma Multiforme-Role in Pathogenesis and Therapeutic Perspective. Int J Mol Sci [Internet]. 2018 Mar 17 [cited 2018 Oct 10];19(3):889.

121. Peng X, Gong F, Chen Y, Jiang Y, Liu J, Yu M, et al. Autophagy promotes paclitaxel resistance of cervical cancer cells: involvement of Warburg effect activated hypoxia-induced factor 1- $\alpha$ mediated signaling. Cell Death Dis [Internet]. 2014 Aug 14 [cited 2018 Mar 22];5(8):e1367e1367.

74. Pollack IF, Hamilton RL, James CD, Finkelstein SD, Burnham J, Yates AJ, et al. Rarity of PTEN deletions and EGFR amplification in malignant gliomas of childhood: results from the Children's Cancer Group 945 cohort. J Neurosurg Pediatr. 2006 Nov;105(5):418-24.

85. Pópulo H, Lopes JM, Soares $P$. The mTOR signalling pathway in human cancer. Vol. 13 , International Journal of Molecular Sciences. 2012. p. 1886-918.

128. Puget $S$, Philippe $C$, Bax DA, Job B, Varlet $P$, Junier $M-P$, et al. Mesenchymal transition and PDGFRA amplification/mutation are key distinct oncogenic events in pediatric diffuse intrinsic pontine gliomas. PLoS One. 2012;7(2):e30313.

21. Rizzo D, Ruggiero A, Martini M, Rizzo V, Maurizi P, Riccardi R. Molecular Biology in Pediatric

This article is protected by copyright. All rights reserved. 
High-Grade Glioma: Impact on Prognosis and Treatment. Biomed Res Int. 2015;2015:1-10.

114. Robert T, Vanoli F, Chiolo I, Shubassi G, Bernstein KA, Rothstein R, et al. HDACs link the DNA damage response, processing of double-strand breaks and autophagy. Nature. 2011;471(7336):74-9.

92. Rodriguez-Rocha H, Garcia-Garcia A, Panayiotidis MI, Franco R. DNA damage and autophagy. Mutat Res Mol Mech Mutagen. 2011 Jun;711(1-2):158-66.

86. Rogers HA, Estranero J, Gudka K, Grundy RG. The therapeutic potential of targeting the PI3K pathway in pediatric brain tumors. Oncotarget. 2017 Jan;8(2):2083-95.

94. Roos WP, Thomas AD, Kaina B. DNA damage and the balance between survival and death in cancer biology. Nat Rev Cancer. 2015 Dec;16(1):20-33.

64. Samuels Y, Ericson K. Oncogenic PI3K and its role in cancer. Curr Opin Oncol. 2006 Jan;18(1):7782.

11. Sanders RP, Kocak M, Burger PC, Merchant TE, Gajjar A, Broniscer A. High-grade astrocytoma in very young children. Pediatr Blood Cancer. 2007 Dec;49(7):888-93.

12. Sands SA, Zhou T, O'Neil SH, Patel SK, Allen J, McGuire Cullen P, et al. Long-Term Follow-Up of Children Treated for High-Grade Gliomas: Children's Oncology Group L991 Final Study Report. J Clin Oncol. 2012 Mar;30(9):943-9.

111. Schwartzentruber J, Korshunov A, Liu X-Y, Jones DTW, Pfaff E, Jacob K, et al. Driver mutations in histone H3.3 and chromatin remodelling genes in paediatric glioblastoma. Nature. 2012 Jan;482(7384):226-31.

27. Shchors K, Massaras A, Hanahan D. Dual Targeting of the Autophagic Regulatory Circuitry in Gliomas with Repurposed Drugs Elicits Cell-Lethal Autophagy and Therapeutic Benefit. Cancer Cell. 2015 Sep;28(4):456-71.

129. Shen J, Zheng H, Ruan J, Fang W, Li A, Tian G, et al. Autophagy inhibition induces enhanced proapoptotic effects of ZD6474 in glioblastoma. Br J Cancer. 2013;109(1):164-71.

103. Shideng Bao, Qiulian Wu, Roger E. McLendon, Yueling Hao, Qing Shi, Anita B. Hjelmeland, Mark W. Dewhirst DDB\& JNR. Glioma stem cells promote radioresistance by preferential activation of the DNA damage response. Nature. 2006;444(7120):756-60.

89. Shin H-JR, Kim H, Kim K II, Baek SH. Epigenetic and transcriptional regulation of autophagy. Autophagy. 2016;12(11):2248-9.

This article is protected by copyright. All rights reserved. 
131. Shingu T, Holmes L, Henry V, Wang Q, Latha K, Gururaj AE, et al. Suppression of RAF/MEK or $\mathrm{PI} 3 \mathrm{~K}$ synergizes cytotoxicity of receptor tyrosine kinase inhibitors in glioma tumor-initiating cells. J Transl Med. 2016 Dec;14(1):46.

72. Song MS, Salmena L, Pandolfi PP. The functions and regulation of the PTEN tumour suppressor. Nat Rev Mol Cell Biol. 2012 Apr;13(5):283-96.

6. Sposto R, Ertel IJ, Jenkin RD, Boesel CP, Venes JL, Ortega JA, et al. The effectiveness of chemotherapy for treatment of high grade astrocytoma in children: results of a randomized trial. A report from the Childrens Cancer Study Group. J Neurooncol. 1989 Jul;7(2):165-77.

152. Spunt SL, Grupp SA, Vik TA, Santana VM, Greenblatt DJ, Clancy J, et al. Phase I Study of Temsirolimus in Pediatric Patients With Recurrent/Refractory Solid Tumors. J Clin Oncol. 2011 Jul;29(21):2933-40.

79. Strickland M, Stoll EA. Metabolic Reprogramming in Glioma. Front cell Dev Biol. 2017;5:43.

23. Sturm D, Bender S, Jones DTW, Lichter P, Grill J, Becher O, et al. Paediatric and adult glioblastoma: multiform (epi)genomic culprits emerge. Nat Rev Cancer. 2014 Feb;14(2):92-107.

43. Sun F, Xu X, Wang X, Zhang B. Regulation of autophagy by Ca2+. Vol. 37, Tumor Biology. 2016. p. $15467-76$.

61. Takeuchi H, Kondo Y, Fujiwara K, Kanzawa T, Aoki H, Mills GB, et al. Synergistic Augmentation of Rapamycin-Induced Autophagy in Malignant Glioma Cells by Phosphatidylinositol 3Kinase/Protein Kinase B Inhibitors. Cancer Res. 2005;65(8).

130. Taylor TE, Furnari FB, Cavenee WK. Targeting EGFR for treatment of glioblastoma: molecular basis to overcome resistance. Curr Cancer Drug Targets. 2012 Mar;12(3):197-209.

155. Thobe K, Sers C, Siebert H. Unraveling the regulation of mTORC2 using logical modeling. Cell Commun Signal. 2017 Dec;15(1):6.

25. Thorburn A, Morgan MJ. Targeting Autophagy in BRAF-Mutant Tumors. Cancer Discov. 2015 Apr;5(4):353-4.

37. Thorburn A. Autophagy and disease. J Biol Chem [Internet]. 2018 Apr 13 [cited 2019 Mar 4];293(15):5425-30.

16. van Tellingen O, Yetkin-Arik B, de Gooijer MC, Wesseling P, Wurdinger T, de Vries HE. Overcoming the blood-brain tumor barrier for effective glioblastoma treatment. Drug Resist Updat. 2015 Mar;19:1-12.

This article is protected by copyright. All rights reserved. 
62. Vanhaesebroeck B, Guillermet-Guibert J, Graupera M, Bilanges B. The emerging mechanisms of isoform-specific PI3K signalling. Nat Rev Mol Cell Biol. 2010 May;11(5):329-41.

134. Varghese F, Bukhari AB, Malhotra R, De A. IHC profiler: An open source plugin for the quantitative evaluation and automated scoring of immunohistochemistry images of human tissue samples. PLoS One. 2014;

138. Vinci M, Burford A, Molinari V, Kessler K, Popov S, Clarke M, et al. Functional diversity and cooperativity between subclonal populations of pediatric glioblastoma and diffuse intrinsic pontine glioma cells. Nat Med. 2018;

35. Wang D, Peng Z, Ren G, Wang G. The different roles of selective autophagic protein degradation in mammalian cells. Oncotarget. 2015 Nov;6(35):37098-116.

13. Warren, E. K. Pediatric high-grade gliomas: survival at what cost? Transl Pediatr. 2012;1(2):1167.

126. Weihua Z, Tsan R, Huang W-C, Wu Q, Chiu C-H, Fidler IJ, et al. Survival of Cancer Cells Is Maintained by EGFR Independent of Its Kinase Activity. Cancer Cell. 2008 May;13(5):385-93.

100. Woo RA, Jack MT, Xu Y, Burma S, Chen DJ, Lee PWK. DNA damage-induced apoptosis requires the DNA-dependent protein kinase, and is mediated by the latent population of p53. EMBO J. 2002 Jun;21(12):3000-8.

99. Woo RA, McLure KG, Lees-Miller SP, Rancourt DE, Lee PW. DNA-dependent protein kinase acts upstream of p53 in response to DNA damage. Nature. 1998 Aug;394(6694):700-4.

112. Wu G, Broniscer A, McEachron TA, Lu C, Paugh BS, Becksfort J, et al. Somatic histone H3 alterations in pediatric diffuse intrinsic pontine gliomas and non-brainstem glioblastomas. Nat Genet. 2012 Mar;44(3):251-3.

19. Wu G, Diaz AK, Paugh BS, Rankin SL, Ju B, Li Y, et al. The genomic landscape of diffuse intrinsic pontine glioma and pediatric non-brainstem high-grade glioma. Nat Genet. 2014 May;46(5):444-50.

26. Yan Y, Xu Z, Dai S, Qian L, Sun L, Gong Z. Targeting autophagy to sensitive glioma to temozolomide treatment. J Exp Clin Cancer Res. 2016 Feb;35:23.

38. Yang Z, Klionsky DJ. Mammalian autophagy: Core molecular machinery and signaling regulation. Vol. 22, Current Opinion in Cell Biology. 2010. p. 124-31.

55. Yang ZJ, Chee CE, Huang S, Sinicrope FA. The role of autophagy in cancer: therapeutic

This article is protected by copyright. All rights reserved. 
implications. Mol Cancer Ther. 2011 Sep;10(9):1533-41.

148. Yao T-W, Zhang J, Prados M, Weiss WA, David James C, Nicolaides T. Acquired resistance to BRAF inhibition in BRAFV600E mutant gliomas. Oncotarget. 2016;8(1):583-95.

157. Yap TA, Bjerke L, Clarke PA, Workman P. Drugging PI3K in cancer: refining targets and therapeutic strategies. Curr Opin Pharmacol. 2015 Aug;23:98-107.

93. Ye H, Chen M, Cao F, Huang H, Zhan R, Zheng X. Chloroquine, an autophagy inhibitor, potentiates the radiosensitivity of glioma initiating cells by inhibiting autophagy and activating apoptosis. BMC Neurol. 2016 Dec;16(1):178.

36. Youle RJ, Narendra DP. Mechanisms of mitophagy. Nat Rev Mol Cell Biol [Internet]. 2011 Jan 1 [cited 2018 Dec 13];12(1):9-14.

87. Yuan H-X, Russell RC, Guan K-L. Regulation of PIK3C3/VPS34 complexes by MTOR in nutrient stress-induced autophagy. Autophagy. 2013 Dec;9(12):1983-95.

77. Zarghooni M, Bartels U, Lee E, Buczkowicz P, Morrison A, Huang A, et al. Whole-Genome Profiling of Pediatric Diffuse Intrinsic Pontine Gliomas Highlights Platelet-Derived Growth Factor Receptor and Poly (ADP-ribose) Polymerase As Potential Therapeutic Targets. J Clin Oncol. 2010 Mar;28(8):1337-44.

140. ZHANG R, WANG R, CHEN Q, CHANG H. Inhibition of autophagy using 3-methyladenine increases cisplatin-induced apoptosis by increasing endoplasmic reticulum stress in U251 human glioma cells. Mol Med Rep. 2015 Aug;12(2):1727-32.

65. Zhao L, Vogt PK. Class I PI3K in oncogenic cellular transformation. Oncogene. 2008 Sep;27(41):5486-96.

106. Zhuang W, Qin Z, Liang Z. The role of autophagy in sensitizing malignant glioma cells to radiation therapy. Acta Biochim Biophys Sin (Shanghai). 2009 May;41(5):341-51.

81. Zou Z, Chen J, Yang J, Bai X. Targeted Inhibition of Rictor/mTORC2 in Cancer Treatment: A New Era after Rapamycin. Curr Cancer Drug Targets [Internet]. 2016 [cited 2018 Dec 12];16(4):288304.

This article is protected by copyright. All rights reserved. 


\section{Funding}

GJP was awarded grant funding from the Ollie Young Foundation and Brain Tumour Research, AH was funded by the Ollie Young Foundation and RH, Brain Tumour Research. P.A.M. is funded by FCT Investigator contract from the Foundation for Science and Technology (FCT), Portugal (ref:IF/00614/2014) and FCT exploratory grant, ref:IF/00614/2014/CP12340006. CBMR is financed by FCT Research Center Grant ref:UID/BIM/04773/2013CBMR1334.

\section{Conflict of Interest}

The authors declare no conflict of interest.

Figure 1. Macro-/micro-, chaperone mediated autophagy and mitophagy. The processes collectively described as 'autophagy' are subdivided by the nature in which substrates for degradation are selected and delivered to the lysosome. Micro-autophagy is a cellular pathway which is mediated by direct lysosomal engulfment of the cytoplasmic cargo. Cytoplasmic material is trapped in the lysosome/vacuole by the random process of membrane invagination. Chaperonedependent autophagy involves the selection of soluble cytosolic proteins that are then targeted to lysosomes and directly translocated across the lysosome membrane for degradation. The unique features of this type of autophagy are the selectivity on the proteins that are degraded by this pathway and the direct shuttling of these proteins across the lysosomal membrane without the requirement for the formation of additional vesicles. Macro-autophagy (typically termed 'autophagy'), is the cellular network where targeted cytoplasmic components are isolated from the cytoplasm within a double-membraned vesicle called an autophagosome. The autophagosome fuses with lysosomes and the contents are degraded, recycled and released back into the cytoplasm. Mitophagy is the selective degradation of mitochondria by autophagy. Mitophagy promotes turnover of mitochondria and prevents the accumulation of dysfunctional mitochondria. Mitophagy is regulated by the PINK1 and parkin proteins.

Figure 2. (Top) Major pathways involved in Autophagy Regulation. Autophagy regulation is complex and tightly regulated, with multiple activators and inhibitors. (Green) Growth factor binding at the cell surface receptors activate PTEN, a major negative regulator of autophagy (shown in red). PTEN dephosphorylates $\mathrm{PIP}_{3}$ to $\mathrm{PIP}_{2}$, inhibiting AKT signalling. PTEN deactivation, or reduction in growth factor signalling permits formation of $\mathrm{PIP}_{3}$, recruiting AKT to the plasma membrane where it is phosphorylated and activated. Activated Akt phosphorylates and inactivates Tuberculosis Sclerosis

This article is protected by copyright. All rights reserved. 
1/2 (TSC1/2), releasing Rheb2 to activate mTORC and inhibiting autophagy. Activated AKT inhibits Foxo3a, ablating transcription of autophagy related genes, including various ATG's and LC3. Abundant amino acids activate Rheb2, activating mTORC and preventing autophagy induction. High ATP/AMP ratio inhibits AMPK, inhibiting TSC1/2 activation and Rheb activation of mTORC1, inhibiting autophagy. In addition, AMPK phosphorylates ULK1, stimulating ULK1 complex and promoting autophagy. Elevated p53, as a result of DNA damage (shown in blue) (and other assaults) activate AMPK and inhibit downstream signalling by Rheb, inhibiting mTORC1 and abolishing downstream autophagy signalling. DNA damage (and elevated glucose) leads to activation of JUN Nterminal kinase (JNK) pathway and phosphorylation of Bcl-2. Phosphorylated $\mathrm{Bcl}-2$ dissociates from Beclin1, allowing Beclin1/VPS34 complex formation and autophagy induction. Glucose (grey), (a major source of ATP, shown in purple) restriction triggers AMPK activation and suppression of mTORC1 (by Rheb). Both elevated and depleted glucose levels may lead to accumulation of ROS leading to endoplasmic reticulum (ER) stress and induction of autophagy by AMPK and JNK networks. Glucose deprivation may also induce a p53/AMPK positive feedback loop, in which p53 is phosphorylation by AMPK, via the ATM kinase, leading to nuclear translocation of $p 53$. AMPK is further activated by p53 transcription targets. (Bottom) Overview of autophagy. Autophagy is negatively regulated by protein kinase AMPK (Adenosine monophosphate activated protein kinase) and mTOR (mammalian target of rapamycin), via phosphorylation of ULK1 complex. During times of stress, including nutrient deprivation or by the action of radio- and chemotherapy, mTORC1 (mammalian target of rapamycin complex1) becomes functionally coupled to ULK1 (UNC-51-like kinase-1)-FIP200 (FAK family kinase-interacting protein of 200kDa)-ATG12-ATG101 complex, which phosphorylates Beclin-1. VPS34-Beclin1 complex, regulated by BCL2 (apoptosis associated) family proteins locate to PAS (phagophore assembly site). ATG9 and VMP1 (vacuole membrane protein) recruit lipids to the phagophore for elongation of the membrane. Autophagosome assembly and maturation involves two ubiquitin-like (UBL) conjugation systems; the light chain (LC3) and ATG12 UBL systems. In the ATG12 UBL system, ATG12 becomes covalently bound to ATG5, catalysed by ATG10 and ATG7. ATG12-ATG5 complex binds to ATG16, and the resulting ATG12-ATG5-ATG16 complex interacts with LC3 UBL system. ATG4 protease, cleaves LC3 at carboxyl terminal allowing ATG3 to covalently bind PE (phosphatidylethanolamine) to LC3 for membrane elongation, cargo recognition and fusion of lysosomes to autophagosome. Cellular organelles and macro-molecules are tagged with Lys63 ubiquitin and are sequestered into double membraned autophagosome during membrane elongation. Autophagosome fuses with lysosome, forming autophagolysosome and are degraded by hydrolase and lysosome enzymes.

This article is protected by copyright. All rights reserved. 
Figure 3. Tumour location, patient survival and tissue microarray staining for key autophagy and proliferation markers. A). 20 patient biopsies were obtained from various regions within the brain. Radius of the circle is proportional to the number of cases. Patient \#19 and \#20, primary tumour location data was absent. B). Overall survival was plotted for this patient cohort and C). Stained for LC3 A/B, Beclin1, Ki67 and Haematoxylin and Eosin staining. Images shown are at 13.5x and (inset) 35.5x magnification. All were obtained using a Hamamatsu NanoZoomer-SQ Digital slide scanner and quantified using an IHC profiler package within ImageJ (134).

Figure 4. Tissue Microarray staining for key autophagy and proliferation markers in an original treatment naïve and relapse pHGG tumour. LC3 A/B, Beclin1, Ki67 and Haematoxylin and Eosin staining was conducted for each core from this patient (grade IV GBM where the original tumour was located within the temporal lobe) in the original and the relapse biopsy samples (following the indicated treatment regimen) and shown at $13.5 \mathrm{x}$ magnification and (inset) $35.5 \mathrm{x}$. Images were obtained using a Hamamatsu NanoZoomer-SQ Digital slide scanner and quantified using an IHC profiler package within ImageJ (134).

Table 1. Clinical trial summary in pHGG. Shown are the various clinical trials and their respective completion stage for pHGG using agents that target (directly or indirectly) autophagy. Included are the respective phase for each trial and the age selection criteria.

This article is protected by copyright. All rights reserved. 


\begin{tabular}{|c|c|c|c|c|c|c|}
\hline Trial ID & Therapeutic(s) & Tumour Type & $\begin{array}{l}\text { Age } \\
\text { (years) }\end{array}$ & Phase & $\begin{array}{l}\text { Primary Outcome } \\
\text { Measure }\end{array}$ & Status \\
\hline NCT01331135 & Sirolimus & $\begin{array}{l}\text { Solid Refractory } \\
\text { Tumours }\end{array}$ & Up to 30 & Phase I & $\begin{array}{l}\text { Maximum tolerated } \\
\text { dose (MTD) }\end{array}$ & $\begin{array}{l}\text { Active, not } \\
\text { yet } \\
\text { recruiting }\end{array}$ \\
\hline NCT01282697 & $\begin{array}{l}\text { Rapamycin and } \\
\text { Iranotecan }\end{array}$ & $\begin{array}{l}\text { Solid Refractory } \\
\text { Tumours }\end{array}$ & $1-21$ & Phase I & $\begin{array}{l}\text { Maximum tolerated } \\
\text { dose (MTD) Dose } \\
\text { limiting toxicity } \\
\text { (DLT) }\end{array}$ & $\begin{array}{l}\text { inactive } \\
\text { since } 2013\end{array}$ \\
\hline NCT01670175 & $\begin{array}{l}\text { Sirolimus, } \\
\text { combined } \\
\text { cyclophosphami } \\
\text { de and } \\
\text { topotecan }\end{array}$ & Solid Tumour & $1-30$ & Phase I & $\begin{array}{l}\text { Dose limiting } \\
\text { toxicity (DLT) }\end{array}$ & Completed. \\
\hline NCT02015728 & $\begin{array}{l}\text { Temozolomide, } \\
\text { Etoposide, } \\
\text { Everolimus plus } \\
\text { Erlotinib, } \\
\text { Dasatinib or } \\
\text { Sorafenib }\end{array}$ & Brain Tumour & $\begin{array}{l}1 \text { month } \\
-30\end{array}$ & Feasibility & $\begin{array}{l}\text { Efficacy, Survival, } \\
\text { Toxicity }\end{array}$ & $\begin{array}{l}\text { Active, not } \\
\text { recruiting }\end{array}$ \\
\hline NCT00187174 & Evirolimus & $\begin{array}{l}\text { Recurrent/ Refractory } \\
\text { Solid including Brain } \\
\text { Tumours }\end{array}$ & $3-21$ & Phase I & $\begin{array}{l}\text { Maximum tolerated } \\
\text { dose (MTD) }\end{array}$ & Completed \\
\hline NCT03387020 & $\begin{array}{l}\text { Everolimus and } \\
\text { Ribociclib }\end{array}$ & $\begin{array}{l}\text { Malignant glioma, } \\
\text { recurrent and } \\
\text { refractory DIPG, } \\
\text { Ependymoma, } \\
\text { Medulloblastoma, ATRT }\end{array}$ & $1-21$ & Phase I & $\begin{array}{l}\text { Maximum tolerated } \\
\text { dose (MTD) Overall } \\
\text { response }\end{array}$ & Recruiting \\
\hline NCT02233049 & $\begin{array}{l}\text { Everolimus, } \\
\text { Erlotinib, } \\
\text { Dasatinib } \\
\text { (Combinatorial) }\end{array}$ & $\begin{array}{l}\text { DIPG with } \\
\text { EGFR overexpression, } \\
\text { PTEN loss or } \\
\text { combination mutations }\end{array}$ & $\begin{array}{l}6 \text { months } \\
-25\end{array}$ & Phase II & $\begin{array}{l}\text { Overall survival ( } 2 \\
\text { years) }\end{array}$ & Recruiting \\
\hline NCT00880282 & $\begin{array}{l}\text { Temsirolimus } \\
\text { and } \\
\text { Cixutumumab }\end{array}$ & $\begin{array}{l}\text { Recurrent/ refractory } \\
\text { solid tumours }\end{array}$ & $1-30$ & Phase I & $\begin{array}{l}\text { Maximum tolerated } \\
\text { dose (MTD) }\end{array}$ & Completed \\
\hline NCT01614795 & $\begin{array}{l}\text { Temsirolimus } \\
\text { and } \\
\text { Cixutumumab }\end{array}$ & $\begin{array}{l}\text { Recurrent/ refractory } \\
\text { solid tumours }\end{array}$ & $1-30$ & Phase II & $\begin{array}{l}\text { Objective response } \\
\text { rate } \\
\text { Toxicity }\end{array}$ & Completed \\
\hline NCT03213678 & $\begin{array}{l}\text { mTOR/DNA-PK } \\
\text { dual inhibitor } \\
\text { LY3023414 }\end{array}$ & Solid tumours & $1-21$ & $\begin{array}{l}\text { Phase II } \\
\text { Paediatirc } \\
\text { MATCH }\end{array}$ & $\begin{array}{l}\text { Response rate ( } 3 \\
\text { years) }\end{array}$ & Recruiting \\
\hline NCT02813135 & $\begin{array}{l}\text { Combinatorial, } \\
\text { including } \\
\text { Everolimus } \\
\end{array}$ & $\begin{array}{l}\text { Recurrent/ Refractory } \\
\text { Tumours, excluding } \\
\text { metastases }\end{array}$ & Up to 18 & $\begin{array}{l}\text { Phase I/ } \\
\text { Phase II }\end{array}$ & $\begin{array}{l}\text { Objective tumour } \\
\text { response Time to } \\
\text { progression. }\end{array}$ & Recruiting \\
\hline NCT01677741 & $\begin{array}{l}\text { Debrafenib } \\
\text { (BRAF V600 } \\
\text { mutant) }\end{array}$ & $\begin{array}{l}\text { Paediatric low and high } \\
\text { grade gliomas with } \\
\text { BRAFV600E mutation }\end{array}$ & $1-17$ & Phase I & $\begin{array}{l}\text { Maximum tolerated } \\
\text { dose (MTD) } \\
\text { Dose limiting } \\
\text { toxicity (DLT) }\end{array}$ & Recruiting \\
\hline NCT01748149 & Vemurafenib & $\begin{array}{l}\text { Recurrent/ Refractory } \\
\text { gliomas }\end{array}$ & Up to 25 & Phase I & $\begin{array}{l}\text { Maximum tolerated } \\
\text { dose (MTD) }\end{array}$ & $\begin{array}{l}\text { Active, not } \\
\text { recruiting }\end{array}$ \\
\hline NCT02684058 & $\begin{array}{l}\text { Dabrafenib and } \\
\text { Trametinib (MEK } \\
1 / 2 \text { inhibitor) }\end{array}$ & $\begin{array}{l}\text { BRAF V600E positive } \\
\text { low grade and } \\
\text { recurrent/refractory } \\
\text { high grade glioma }\end{array}$ & $1-25$ & Phase II & $\begin{array}{l}\text { Overall response } \\
\text { rate (ORR) over } 4 \\
\text { months }\end{array}$ & Recruiting \\
\hline NCT00883688 & $\begin{array}{l}\text { Bevacizumab } \\
\text { and labatinib }\end{array}$ & Ependymoma & Up to 21 & Phase II & $\begin{array}{l}\text { Objective response } \\
\text { rate }\end{array}$ & Completed, \\
\hline
\end{tabular}

This article is protected by copyright. All rights reserved. 


\begin{tabular}{|c|c|c|c|c|c|c|}
\hline NCT03696355 & $\begin{array}{l}\text { GDC-0084 PI3K } \\
\text { inhibitor }\end{array}$ & $\begin{array}{l}\text { Peadiatric high grade } \\
\text { glioma }\end{array}$ & $2-21$ & Phase I & $\begin{array}{l}\text { Maximum tolerated } \\
\text { dose (MTD) after } \\
\text { radiotherapy }\end{array}$ & Recruiting \\
\hline NCT01158300 & $\begin{array}{l}\text { PTC299 VEGF } \\
\text { inhibitor }\end{array}$ & $\begin{array}{l}\text { Recurrent or refractory } \\
\text { CNS tumours }\end{array}$ & $3-21$ & Phase I & $\begin{array}{l}\text { Maximum tolerated } \\
\text { dose (MDT) Adverse } \\
\text { events }\end{array}$ & Completed \\
\hline NCT00077454 & $\begin{array}{l}\text { Erlotonib }+ \\
\text { temozolomide }\end{array}$ & $\begin{array}{l}\text { Recurrent/ refractory } \\
\text { solid tumours }\end{array}$ & Up to 21 & Phase I & $\begin{array}{l}\text { Maximum tolerated } \\
\text { dose (MDT) Dose } \\
\text { limiting toxicity } \\
(\mathrm{DLT})\end{array}$ & Completed \\
\hline NCT03654716 & $\begin{array}{l}\text { ALRN-6924 dual } \\
\text { MDM2/MDMX } \\
\text { inhibitor }\end{array}$ & $\begin{array}{l}\text { Solid tumours including } \\
\text { brain tumour }\end{array}$ & $1-21$ & Phase 1 & $\begin{array}{l}\text { Dose limiting } \\
\text { toxicity (DLT) }\end{array}$ & Recruiting \\
\hline
\end{tabular}

This article is protected by copyright. All rights reserved. 
Figure 1.

\section{Microautophagy.}

Cytoplasmic cargo
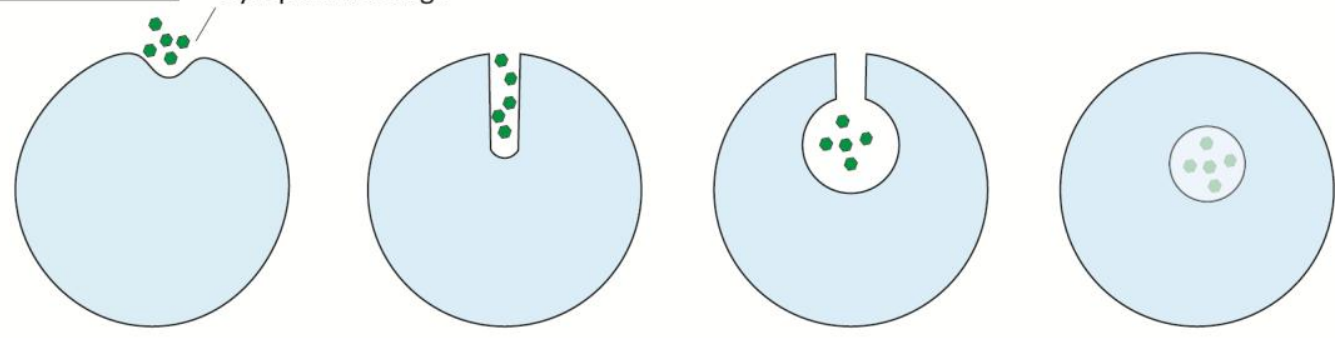

\section{Chaperone Mediated Autophagy (CMA)}
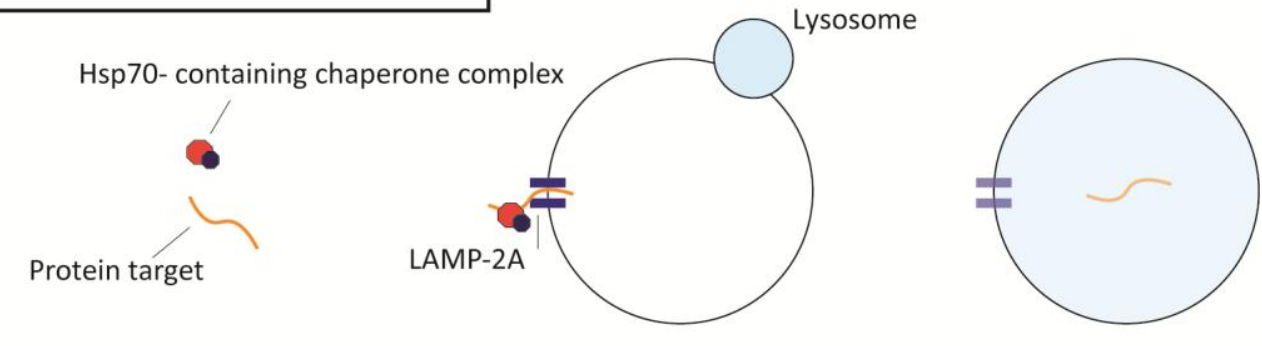

\section{Macro Autophagy.}
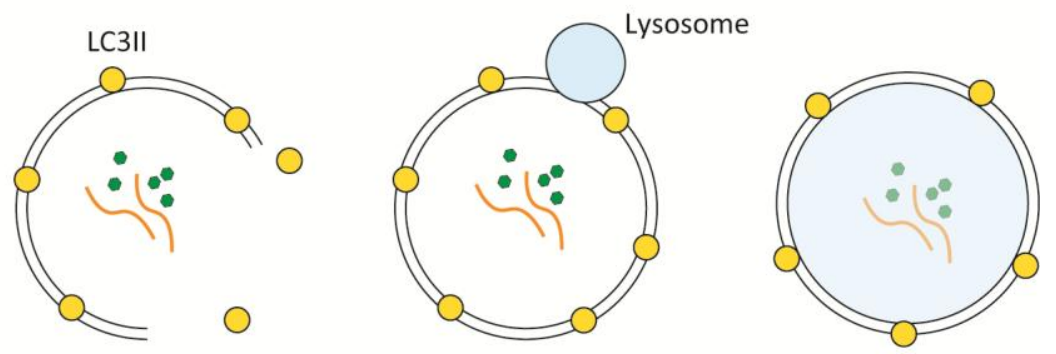

\section{Selective Macro Autophagy (Mitophagy).}
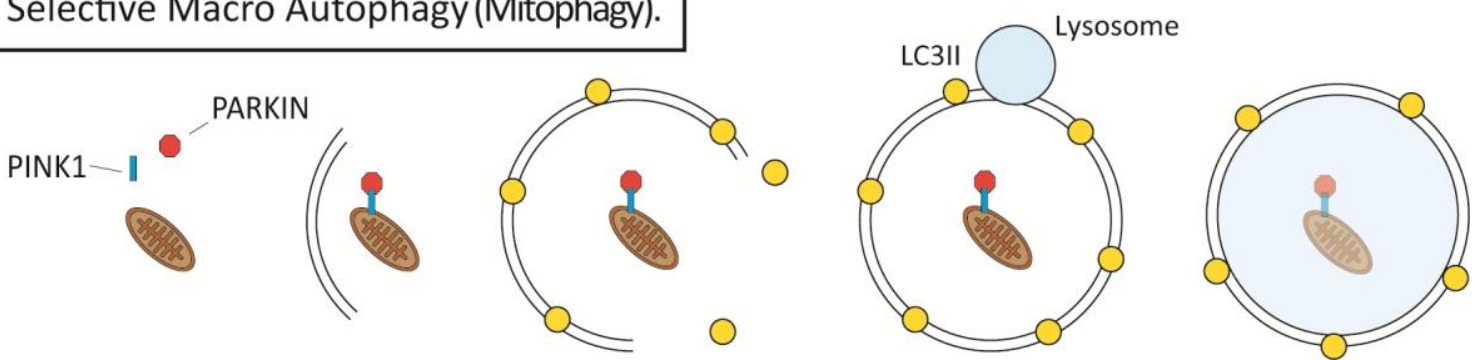

This article is protected by copyright. All rights reserved. 


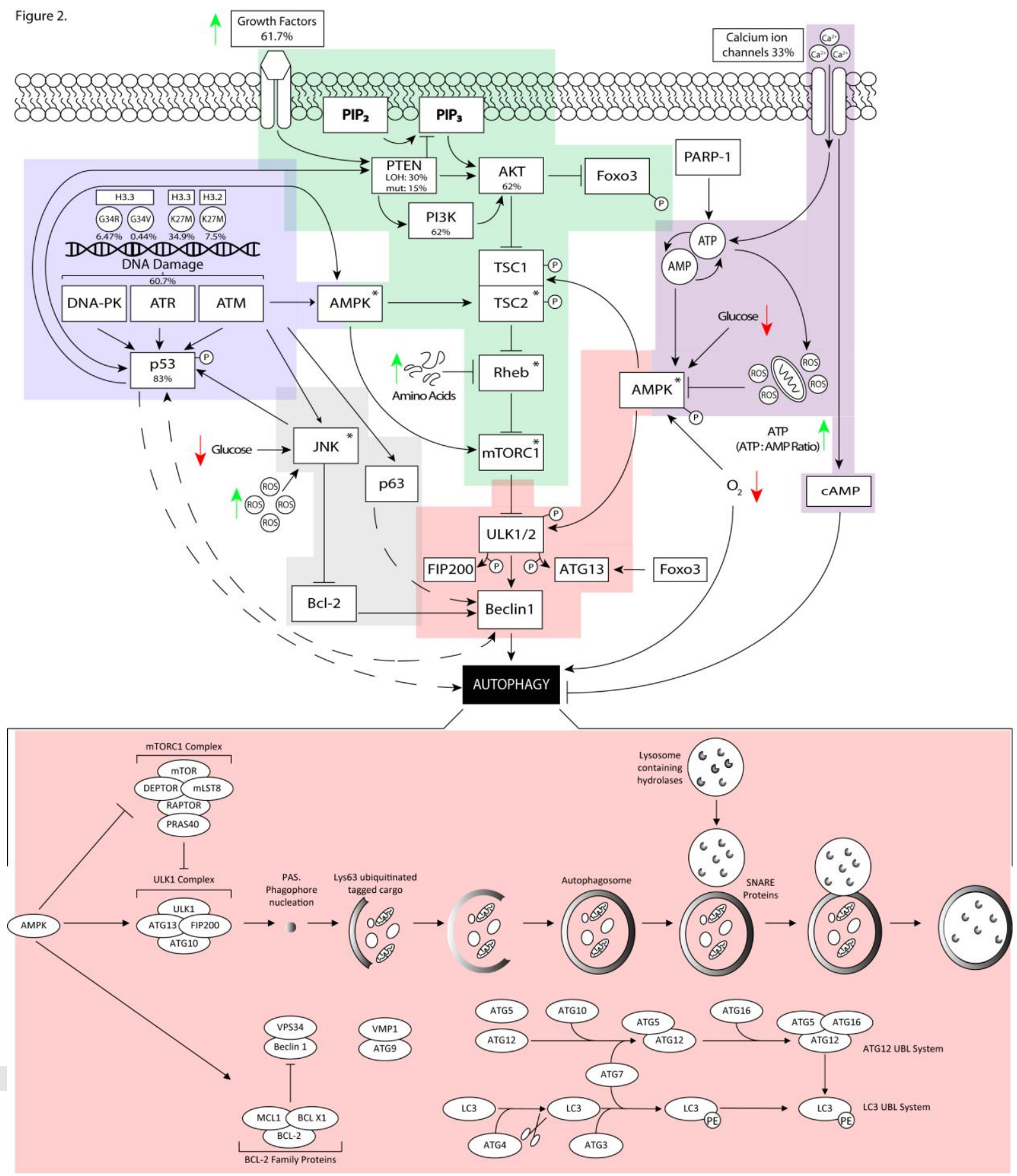

This article is protected by copyright. All rights reserved. 

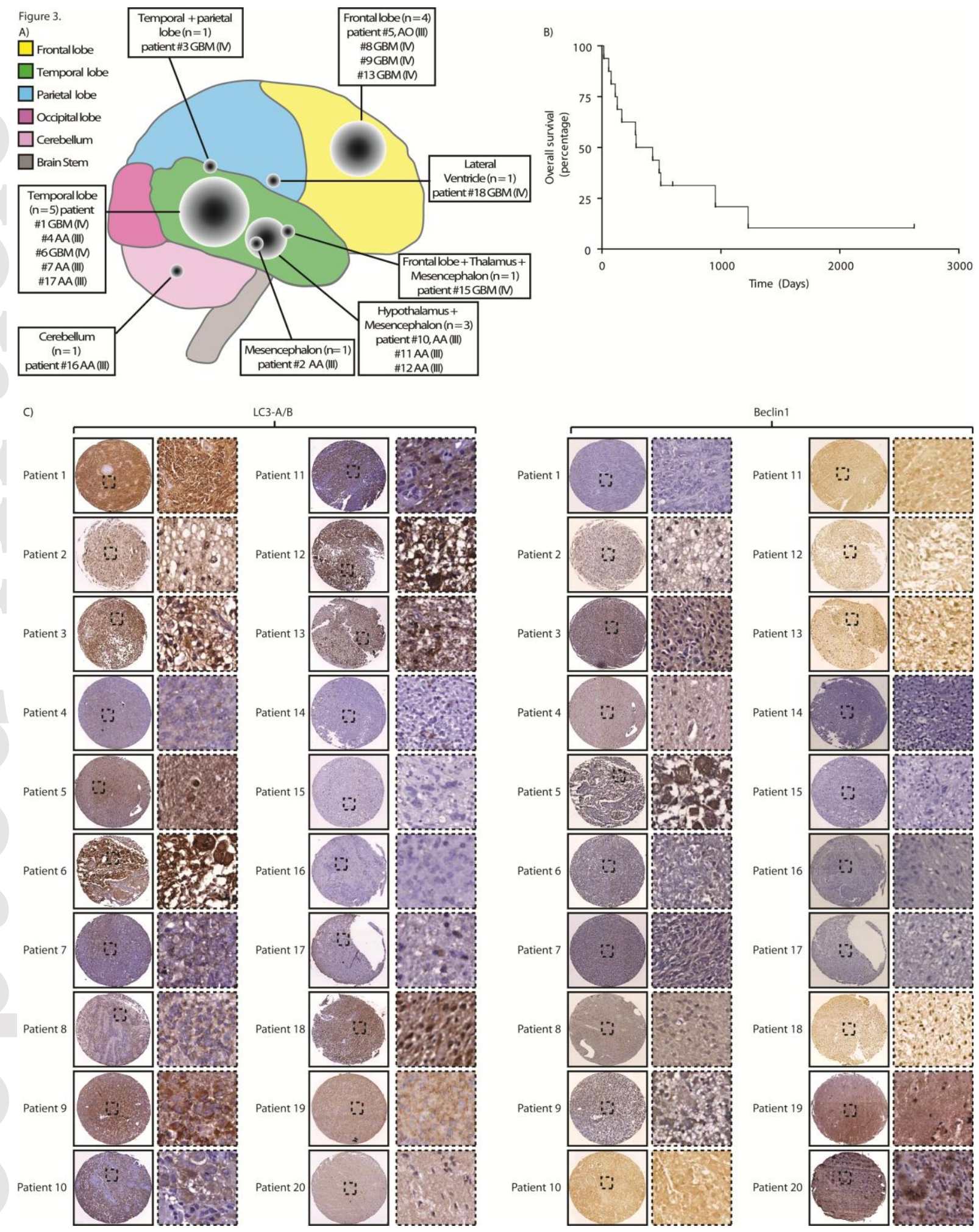

This article is protected by copyright. All rights reserved. 
Figure 4.

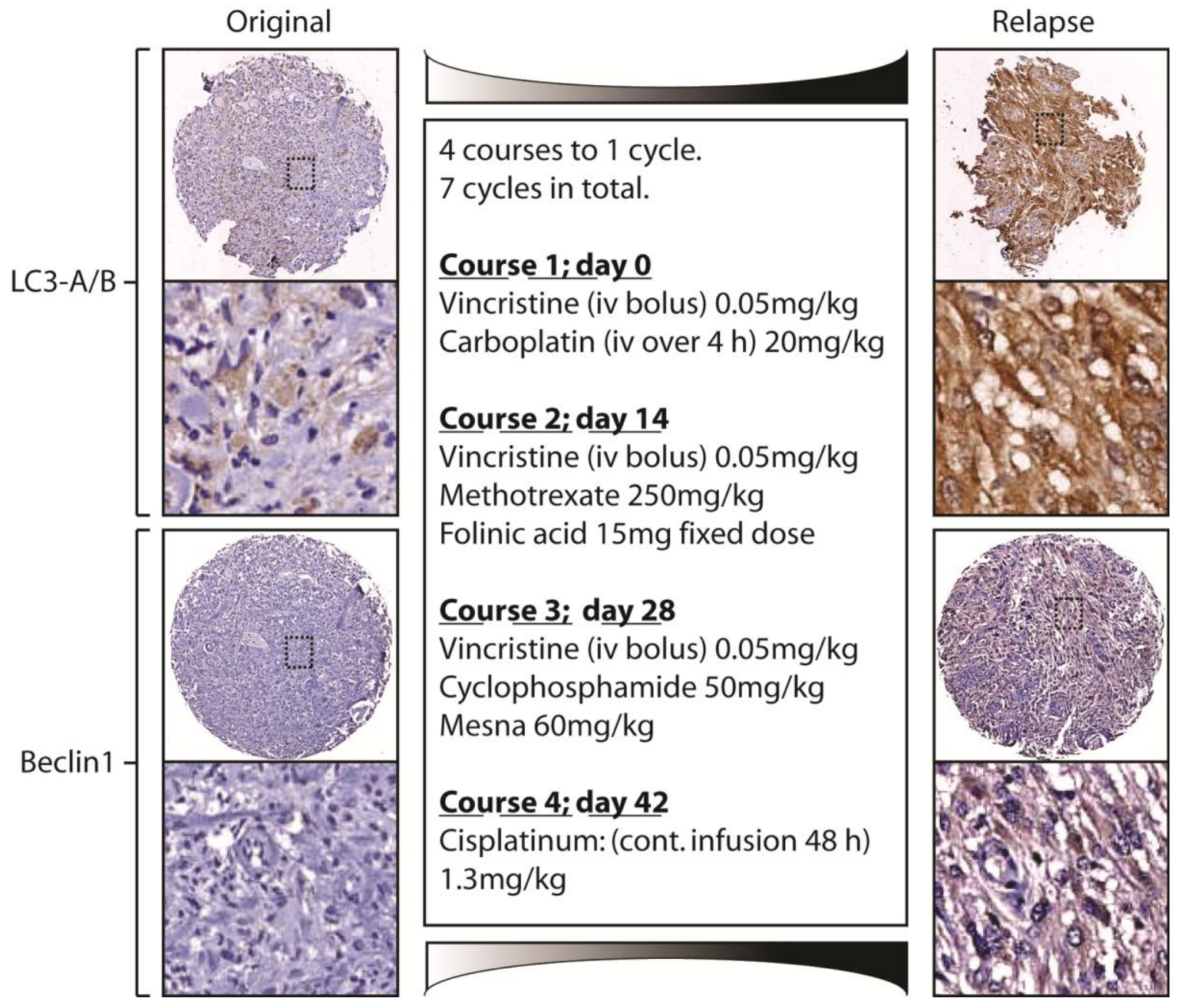

This article is protected by copyright. All rights reserved. 